\title{
Comprehensive Review Tapered Optical Fiber Configurations for Sensing Application: Trend and Challenges
}

\author{
Bakr Ahmed Taha ${ }^{1} \mathbb{D}$, Norazida Ali ${ }^{1}{ }^{\mathbb{D}}$, Nurfarhana Mohamad Sapiee $^{1}$, Mahmoud Muhanad Fadhel ${ }^{1}$, \\ Ros Maria Mat Yeh ${ }^{1}$, Nur Nadia Bachok ${ }^{1}$, Yousif Al Mashhadany ${ }^{2}$ (D) and Norhana Arsad ${ }^{1, *(D)}$
}

1 Department of Electrical, Electronic and Systems Engineering, Faculty of Engineering and Built Environment, Universiti Kebangsaan Malaysia, UKM, Bangi 43600, Malaysia; p103537@siswa.ukm.edu.my (B.A.T.); p96194@siswa.ukm.edu.my (N.A.); p103517@siswa.ukm.edu.my (N.M.S.); p97209@siswa.ukm.edu.my (M.M.F.); p100898@siswa.ukm.edu.my (R.M.M.Y.); p110441@siswa.ukm.edu.my (N.N.B.)

2 Department of Electrical Engineering, College of Engineering, University of Anbar, Ramadi 00964, Anbar, Iraq; yousif.mohammed@uoanbar.edu.iq

* Correspondence: noa@ukm.edu.my

Citation: Taha, B.A.; Ali, N.; Sapiee, N.M.; Fadhel, M.M.; Mat Yeh, R.M.; Bachok, N.N.; Al Mashhadany, Y.; Arsad, N. Comprehensive Review Tapered Optical Fiber Configurations for Sensing Application: Trend and Challenges. Biosensors 2021, 11, 253. https://doi.org/10.3390/bios11080253

Received: 8 July 2021

Accepted: 23 July 2021

Published: 27 July 2021

Publisher's Note: MDPI stays neutral with regard to jurisdictional claims in published maps and institutional affiliations.

Copyright: (C) 2021 by the authors Licensee MDPI, Basel, Switzerland. This article is an open access article distributed under the terms and conditions of the Creative Commons Attribution (CC BY) license (https:// creativecommons.org/licenses/by/ $4.0 /$ )

\begin{abstract}
Understanding environmental information is necessary for functions correlated with human activities to improve healthcare quality and reduce ecological risk. Tapered optical fibers reduce some limitations of such devices and can be considerably more responsive to fluorescence and absorption properties changes. Data have been collected from reliable sources such as Science Direct, IEEE Xplore, Scopus, Web of Science, PubMed, and Google Scholar. In this narrative review, we have summarized and analyzed eight classes of tapered-fiber forms: fiber Bragg grating (FBG), long-period fiber grating (LPFG), Mach-Zehnder interferometer (MZI), photonic crystals fiber (PCF), surface plasmonic resonance (SPR), multi-taper devices, fiber loop ring-down technology, and optical tweezers. We evaluated many issues to make an informed judgement about the viability of employing the best of these methods in optical sensors. The analysis of performance for tapered optical fibers depends on four mean parameters: taper length, sensitivity, wavelength scale, and waist diameter. Finally, we assess the most potent strategy that has the potential for medical and environmental applications.
\end{abstract}

Keywords: tapered optical fiber; optical sensors; Bragg grating; microstructure; refractive index sensor

\section{Introduction}

Understanding environmental information is necessary for the correct functioning of processes associated with individual actions to improve indoor and outdoor conditions [1]. However, it needs monitoring and management of essential environmental factors that may be classified into physical parameters such as temperature, pressure, humidity, and biological characteristics, such as concentration of contaminants and bio-hazards, and pathogens, such as viruses [2]. Over the years, optical sensors have become an attractive topic for researchers in many applications due to their benefits such as compact size, low weight, electromagnetic protection, high stability, and the ability to study sensor arrays remotely. Fiber Bragg grating (FBG) devices are based on a diffraction grating. The concept of grating refers to periodic core refractive index change. When light passes through the grating structure, it reflects a portion of each grating layer [3-5]. Long-period fiber grating (LPFG) has periods ranging from hundreds of microns to millimeters, linking incoming light led by a propagation direction in the core to various forward-propagating cladding modes of high diffraction order $\mathrm{m}$ in an optical fiber, which fade fast due to scattering losses [6-8]. A Mach-Zehnder interferometer (MZI) measures the relative phase shift changes between two beams formed by dividing light from a single source. Many applications were covered, such as couplers, ring resonators, splitters, tapers, gates, and 
terminators $[9,10]$. A photonic crystal fiber $(\mathrm{PCF})$ is a periodical optical nanostructure that controls photon mobility [11]. Surface plasmon resonance (SPR) SPR is the resonant vibration of charged electrons at the interface of negative and positive permeability material by generated light to detect material absorption on planar metal (commonly gold/silver) surfaces [12,13]. Multi-taper devices are integrated by two types of fiber (single-mode /multi-mode) [14]. Optical fiber loop ring-down (FLRD) links two optical couplers into the optical ring $[15,16]$. Optical tweezers are formerly known as single-beam gradient force traps that capture and manipulate tiny particles using a highly powerful laser beam $[17,18]$.

\section{Background}

In this part, we will provide a selection of current literature covering a wide range of research techniques and biological systems. In the 1960s, many studies have attempted to develop optical fiber in different fields such as communication, medicine, the environment, and many others. Essentially, optical sensing originated from fiber communication. The employment of lasers with optical fiber enables accurate and sensitive detection compared with other techniques. This method has the advantage of notable features such as interference resistance, adaptability, real-time parameter monitoring, and small size [19-23]. Many optical fiber structures use lasers such as FBG, fiber-optic interferometer, optical fiber MZI, buffer structure, Fabry-Perot, directional couplers, and optical fiber waveguides to a biosensor [24-28]. Tapered fiber production has been shown to employ several processes, including laser ablation, electron beam lithography, vapor-liquid-solid operations, and fiber pulling. Among these processes, flame heating is one of the most adaptable to produce tapered fibers with good physical properties [29-31]. Optical sensors can detect changes in optics properties such as refractive index (RI), absorption, reflection, and fluorescence related to the physical parameters of the investigated environment such as pressure, strain, temperature, and chemical composition. In contrast, it is simple to create optical sensors by guiding light to and collecting light from the measuring location, a process known as extrinsic sensing [32], or by using the fiber itself as the transducer, a technique known as intrinsic sensing [33]. Assessment approaches based on optical fibers received considerable attention in various analytical fields, including chemical and biological sensing, environmental and structural health monitoring, and medical diagnostics. Their vast range of designs and methods enable optical fibers to construct sensitive and selective sensors for real-world circumstances [34-36]. The tapered fiber technique is one of the most widely used in the production of optical sensor components. The tapered fiber technique uses the evanescent wave (EW) tapered-propagating mode to determine RI or chemical composition properties [37]. Recently, tapered optical fibers have been used to create sensors including polarizers, sub-micron wire, light amplification, and near-field microscopy [38-42]. As shown in the literature, the shape of the tapered fiber is critical to its sensor function, with lower diameter taper waists giving increased sensitivity [43,44]. Additionally, tapered fiber optics may be used as light probes to evaluate characteristics of interest with spatial precision on the scale of micrometers, allowing direct examination of biological samples at a cellular level [45]. A study shows the relationship between the integrated photon intensity with particle size and tip radius by scanning tunneling microscopy. The isochromatic photon map varies with the wavelength and geometric asymmetry of the STM tip [46]. In recent years, optical fiber tweezers have garnered significant attention in optical trapping because of their ease of manipulation and design that is small and easy to fabricate [47]. A study shows the use of spectral-width tapered FBG in microsurgical force sensors [48]. Label-free sensors use taper fiber and FBG to identify various cancers [49]. 


\section{Overview of Tapered Fiber}

Optical fiber is divided into two types depending on the number of modes (single mode fiber (SMF) and multi-mode fiber (MMF)) and refractive index (RI). In SMF, only one kind of light beam may propagate through the fiber core with a diameter of 5-10 $\mu \mathrm{m}$ and $125 \mu \mathrm{m}$ of cladding mode. In MMF, multiple light beam modes can propagate in the fiber core with diameter (50-100) $\mu \mathrm{m}$ and $125 \mu \mathrm{m}$ of cladding mode [50,51]. In contrast, tapered fibers are created by stretching a conventional SMF to generate a reduced core diameter shape at the lowest diameter named as the waist. In addition, the waist is a transition zone whose cladding and core diameters decrease when the SMF rated size decreases to the order of micrometer or even nanoscale. The field distribution shifts as the wave propagates through the transition zones due to the change in core/cladding diameters along the path. Thus, energy transfers change with the rate of diameter change, resulting in the loss of propagating wave power and increase loss with the built tapered fiber $[52,53]$. Flame heating techniques and lasers are used to generate tapered optical fibers. Besides, the tapered length, waist diameter, and refractive index (RI) parameters have been influential in optical properties [54]. Fiber tapers are classified into two types, adiabatic and non-adiabatic. In adiabatic designs, the angle of the taper transition area is a modest $10^{-4}-10^{-3} \mathrm{rad}$ and the optical fiber cylinder symmetric is maintained (with a taper diameter ratio to the core beginning diameter $a / a_{0}$ between 0.2 and 1 ), resulting in most optical power remaining in the basic mode. The non-adiabatic taper, on the other hand, has a larger taper angle $[55,56]$. Standard tapered fiber schematic depiction is shown in Figure 1.

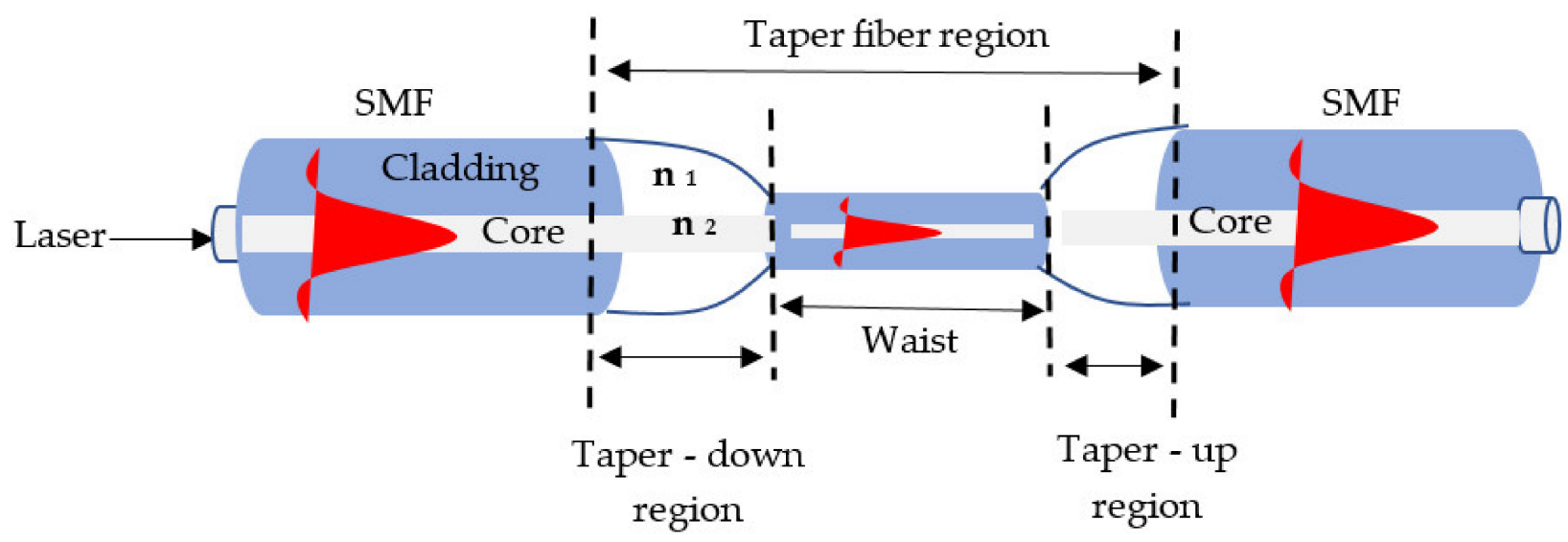

Figure 1. Schematic illustration of the tapered fiber standard [56].

\section{Taxonomy of Literature Review on Tapered Optic Fiber}

Our review selected, evaluated, and analyzed (22) empirical research on optical sensors based on tapered optic fiber, as shown in Table 1. We extract relevant literature from academic databases, such as Science Direct, which provides diverse scientific research across all fields; Scopus, which provides extensive coverage of work from all disciplines; Web of Science, which demonstrates a comprehensive range of various topics in all literature; IEEE, which is recognized as scientifically accurate and pro-science. The section that follows offers a taxonomy of tapered fiber structures and a literature review, as shown in Figure 2. 


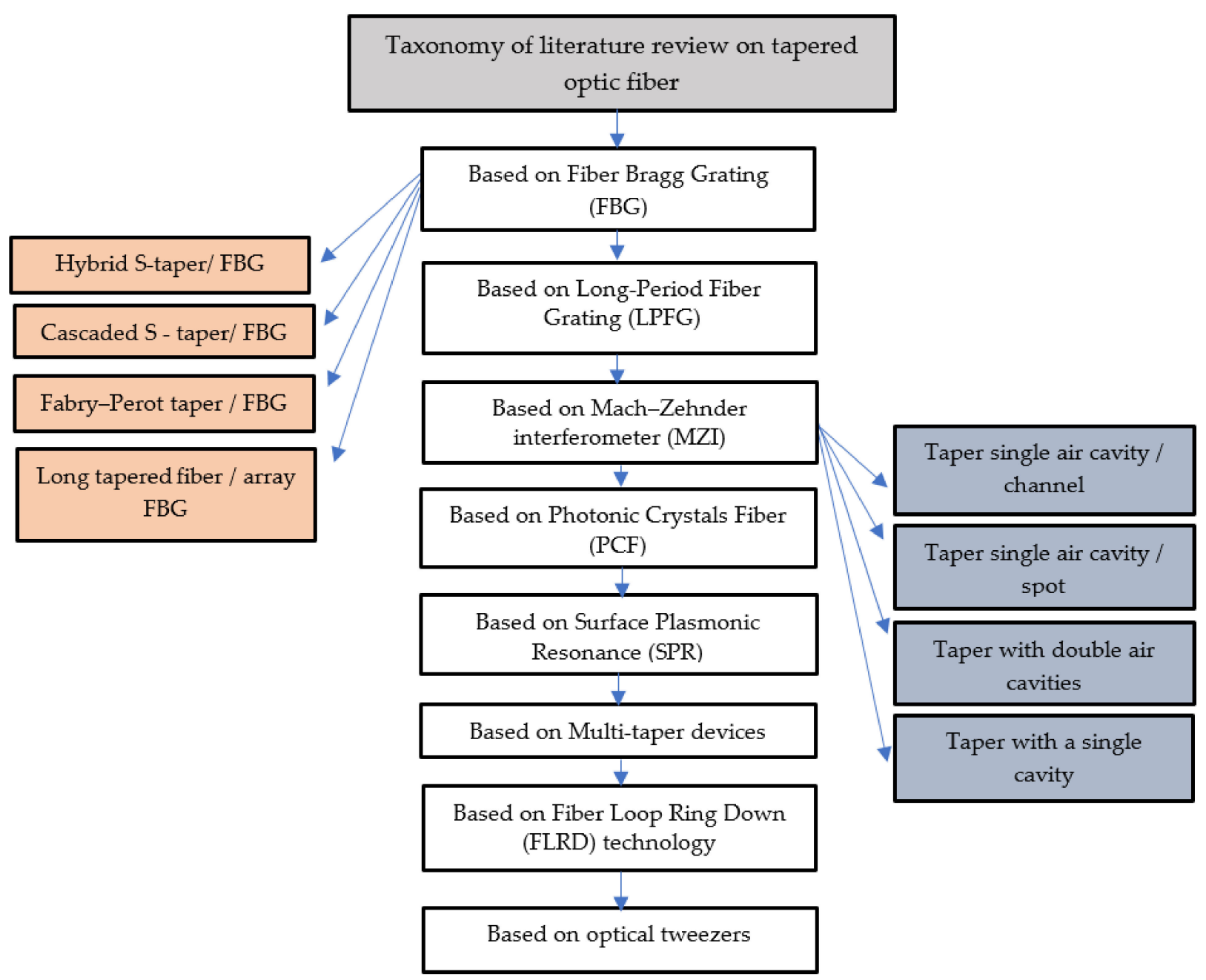

Figure 2. Taxonomy of literature research on tapered optic fiber.

\subsection{Based on Fiber Bragg Grating (FBG)}

FBG techniques are widely employed in photonics sensors devices, having many forms: uniform, chirped, and superstructure [57,58], and some research investigated laser fiber cavities and optical processors to manage complicated optical signals using the FBG technique [59-61]. Figure 3 shows tapered fiber based on FBG structures.

\subsubsection{Hybrid S-Taper/FBG Structure}

A study has proposed a temperature-compensated fiber laser refractometer based on a compact hybrid S fiber taper (SFT)/FBG form. SFT assists as both a sensor and a band-pass filter (BPF) to customize the FBG reflection, a microsize of $0.78 \mathrm{~mm}$. The surrounding refractive index can control the erbium-doped fiber ring laser (FRL) output power due to the RI-dependence intra-cavity loss (SRI). The refractometer has a high sensitivity of $269.76 \mathrm{~dB} / \mathrm{RIU}$ across the measuring range of 1.3330-1.4060 [62]. Because of the big bending radius, the cladding layer is activated at the initial bending region, as light propagates in the SFT; at the second bending area, the stimulated cladding modes are partially back into the core. The transmission spectrum is described by Equation (1) [62].

$$
I=I_{c o r}+I_{c l a}+2 \sqrt{I_{c o r} \cdot I_{c l a}} \cos \left(2 \pi \Delta n_{e f f} \cdot L_{e f f} / \lambda\right)
$$

where $I_{c o r}$ and $I_{c l a}$ indicate the intensity of the core and cladding modes, respectively, $n_{e f f}$ denotes the effective RI difference between the core and cladding modes, $L_{e f f}$ denotes 
the interferometer effective length, and $2 \pi \Delta n_{e f f}$ is the phase deviation between the core and cladding.

\subsubsection{Cascaded S Fiber Taper/FBG Structures}

A dual-point fiber sensor for RI characteristics uses a tiny $\mathrm{S}$ fiber taper cascaded (SFTC) with Bragg grating suggested. It achieved the multiplexing capability of the sensor by cascading. The RI sensitivities range was 1.3540-1.3810, and sensing point 1 and sensing point 2 reached $459.974 \mathrm{~nm} / \mathrm{RIU}$ and $420.781 \mathrm{~nm} / \mathrm{RIU}$, respectively. RI sensor benefits from a small sensing zone, a well-defined interference pattern, and a high RI sensitivity, allowing it to be utilized as a low-cost RI sensor with multiplexing capabilities. This technique shows the benefits of compact size, simple construction, and high accuracy [63]. An optical sensor that uses dual parameters to detect temperature and pressure was reported. The two major sensing structures are a cascaded Bragg fiber grating and a ball-shaped extrinsic Fabry-Perot interferometer. The taper is produced by extending it under the effect of a fusion-splicer arc discharge. Additionally, use the femtosecond laser to make a point-by-point direct method and a Bragg grating in the taper region. The results were in the temperature range of 40 to $400{ }^{\circ} \mathrm{C}$ and 0 to $2 \mathrm{MPa}$ [64]. The Bragg phasematching condition may characterize the connection between the shape of the grating and its reflection properties, as shown in Equation (2) [64].

$$
\lambda_{B}=2 n_{e f f} \cdot \Lambda
$$

where $\lambda_{B}$ denotes the Bragg resonance wavelength, $n_{e f f}$ denotes the fiber core effective index, and $\Lambda$ denotes the grating pitch, and the phase difference in the two reflected laser beams is given in Equation (3).

$$
\frac{4 \pi n L}{\lambda_{m}}+\phi_{0}=(2 m+1) \pi
$$

where $m$ is a positive integer, $\lambda_{m}$ is the wavelength of the order interference dip, and spectrum fringe spacing can be calculated in Equation (4).

$$
\Lambda_{F P}=\frac{\lambda^{2}}{2 n L}
$$

\subsubsection{Fabry-Perot/Tapered FBG}

According to a literature survey, Fabry-Perot interferometers (FPIs) have several essential properties such as low cost, high resolution, electro-magnetic interference avoidance, compact, and reliability $[65,66]$, and they are widely used for various sensing measurements, including temperature, strain, and gas pressure $[67,68]$. A study shows a strain sensing FP sensor system based on tapered FBG. The fiber taper into the capillary with FBG was employed [69,70]. A new in-line FP strain sensor based on a tapered FBG-in-capillary construction to detect temperature was proposed. It is created by inserting a fiber taper containing FBG into a capillary, resulting in an ultra-long active length and an ultra-short interference length and a strain sensitivity of $1129.44 \mathrm{pm} / \mu \varepsilon$. The intensity of reflection of FP can be calculated by Equation (5) [70].

$$
I=I_{1}+I_{2} 2 \sqrt{I_{1}-I_{2}} \cos \left(\frac{4 \pi \cdot n_{a i r} \cdot L_{F P}}{\lambda} \phi_{0}\right)
$$

where $I_{1}$ and $I_{2}$ are the intensity of two reflection rays, $n_{\text {air }}$ is the air refractive index, $\lambda$ is the light wavelength, and $\phi_{0}$ is initial phase difference.

$$
\lambda_{m}=\frac{2 n_{\text {air }} \cdot L_{F P}}{m+1 / 2}
$$


Assuming, $\phi_{0}=0$, when $4 \pi \cdot n_{\text {air }} \cdot \frac{L_{F P}}{\lambda}=(2 m+1) \pi, m$ (an integer) $\lambda_{m}$ is the wavelength of order resonance dip as shown above in Equation (6) [70]. The free spectral range (FSR) of the interference fringe of the FPI can be calculated using Equation (7) [70].

$$
F S R=\lambda_{\text {dip }}(m)-\lambda_{\text {dip }}(m-1) \approx \frac{\lambda^{2}}{2 n_{\text {air }} L_{F P}}
$$

\subsubsection{Long Tapered Fiber/Array of FBG}

Insights drawn from scholarly literature are supplemented with the FBG tapered techniques. Typically, long tapered fiber with an array of FBG is based on altering the fiber diameter through manufacturing. An array FBG was inscribed during the drafting process to create a tapered optical fiber with an adiabatic transition from single mode to become a few-mode part. The reflected signal from the tapered fiber has a spectral width of $4 \mathrm{~nm}$. At some wavelengths, the reflected signal intensity might reach up to 5\%. [71]. The long tapered fiber method based on diameter was altered by a factor of 1.5, which was severely constrained by weakening the optical fiber light-guiding characteristics with decreasing frequency value [72]. However, increasing fiber diameter can be considered without affecting fiber wave guiding characteristics, but it results in a few-mode propagation regime and signals quality degradation. FBG reflects light at a specific wavelength and broadcasts light at all other wavelengths due to the refractive index variation caused by the exposure of the fiber core to ultraviolet radiation.

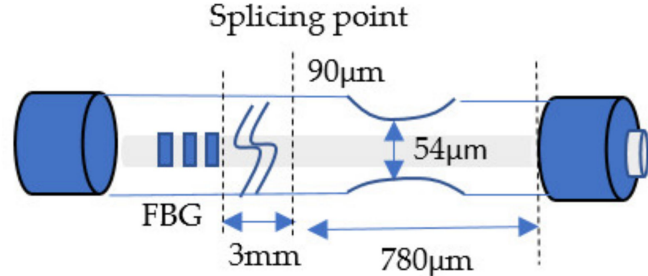

(a)

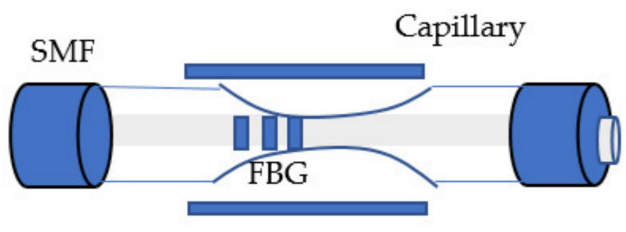

(c)

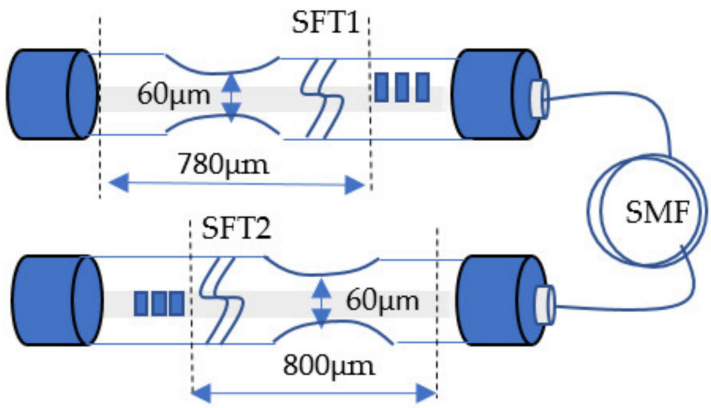

(b)

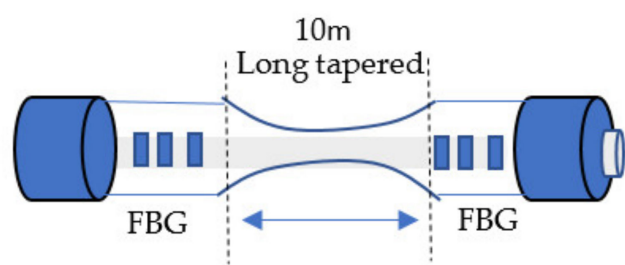

(d)

Figure 3. Tapered fiber optic based on FBG structures. (a) Illustration of hybrid S-taper/FBG structure [62]. (b) Illustration of cascaded S-taper/FBG structure [63]. (c) Illustration of Fabry-Perot/tapered FBG structure [70]. (d) Illustration of long tapered fiber/array of FBG structure [71,72].

\subsection{Based on Long-Period Fiber Grating (LPFG)}

A fiber sensor based on the LPG method was presented in other studies, which utilized a tapered fiber. It transfers light coupled to cladding modes to a biconically optical taper across a liquid phase gap LPG. This type of structure allows for the monitoring of the LPG characteristics employed in devices or systems and the construction of some specific devices [73,74]. The authors present tapered fiber optic sensors based on LPG for detection in chemistry and biology. The sensor is built using a low-cost arc heating method to inscribe periodic microtapers in a single fiber optic. SMF periodic tapering allows for 
coupling of the fundamental core mode to the cladding mode generated by a transmission spectrum resonant frequency. The resonant wavelength varies linearly as the refractive index changes. Experimentally established refractive index sensitivity of $8188 \mathrm{~nm} / \mathrm{RIU}$, which is substantially higher than previously published RI sensitivity values for LPG sensors. However, the sensitivity is controlled by periodic tapers, grating length, and waist diameter $[75,76]$. A periodic tapered LPFG is a selection-based filter with a transmission spectrum similar to a conventional LPFG but with several resonances caused by coupling between the main guided mode $L P_{o 1}, L P_{o r}$ cladding modes resonance wavelengths as shown in Equation (8) [77].

$$
\lambda_{r}=\left(n_{e f f}^{c o r}-n_{e f f}^{c l a, r}\right) \Lambda / q
$$

where, $\Lambda$ is the period of the grating, $\lambda_{r}$ is the resonance wavelength, $n_{e f f}^{c o r}$ and $n_{e f f}^{c l a, r}$ denote the effective refractive, $r$ is order cladding mode, respectively, and $q$ denotes order of diffraction. Consequently, the resonance wavelength coupled the guided mode to the cladding mode with the narrow transmission spectrum due to the high attenuation cladding layer. In refractive index sensing, the relationship between the resonant wavelengths and the RI of the external medium is represented in Equation (9) [78]

$$
\frac{d \lambda_{r}}{d n_{\text {ext }}} \lambda_{r} \delta \varepsilon_{\text {ext }}
$$

where $\delta$ is the overall sensitivity factor, and $\varepsilon_{\text {ext }}$ is the LPFG response coefficient to fluctuation in the external RI. The glass is crushed axially by applying several arc discharges throughout the length of the fiber [79]. However, the periodic changes in the diameter result in a tapered LPFG. The periodical taper area generates evanescent waves, and lights leak out. The effective eigenmode RI would be considerably altered. Figure 4 shows tapered fiber based on long-period fiber grating (LPFG) structure.

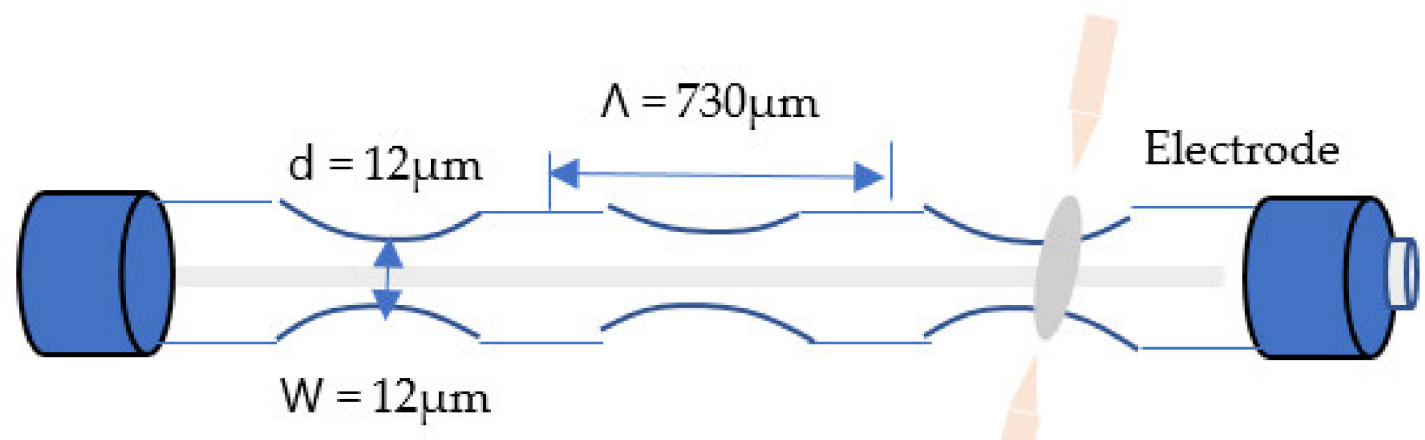

Figure 4. Tapered fiber optic based on long-period fiber grating (LPFG) structure [75].

\subsection{Based on Mach-Zehnder Interferometer (MZI)}

The MZI method is a sort of interferometer dividing the emitting light beam from one source to two collimated beams. MZI can monitor optical path changes between light/medium after splitting and a $3 \mathrm{~dB}$ splitter is required. In addition, the two split lights only cross MZI. Furthermore, MZI has been widely used in optical fiber sensing technology, and several methods in modern years have been suggested [80-83]. Figure 5 shows tapered fiber optic based on Mach-Zehnder (MZI) structures.

\subsubsection{Taper with a Single Cavity}

The tip of the optical sensor is manufactured using the following ways: femtosecond laser, fusion splicing, and heating and pulling processes [84]. An ultra-compact microfiber sensor head for high-temperature detection is presented. The method was a Mach-Zehnder interferometer based on an inner air cavity. The refractive index sensitivity 
was $4202 \mathrm{~nm} / \mathrm{RI}$ [85]. The sensitivity of stress can be defined as shown in Equation (10), to measure temperature, RI, and strain, where $m$ is an integer, $L$ is the cavity length, $\lambda$ is the wavelength, $\Delta n_{e f f}^{\text {clad }}, \Delta n_{e f f}^{\text {air }}$ is the RI difference between the core/air-cavity mode, and $\varepsilon$ is the strain $[82,86]$.

$$
\frac{\Delta \lambda_{\text {dip }}}{\Delta \varepsilon}=\frac{2}{2 m+1}\left[\Delta n_{e f f} \frac{\Delta L}{\Delta \varepsilon}+L\left(\frac{\Delta n_{e f f}^{\text {clad }}}{\Delta \varepsilon}-\frac{\Delta n_{e f f}^{\text {air }}}{\Delta \varepsilon}\right)\right] \varepsilon=\frac{\Delta L}{L}
$$

Because of this equation's hypothesis $\left[\begin{array}{l}\Delta \lambda_{1} \\ \Delta \lambda_{2}\end{array}\right]=\left[\begin{array}{ll}K T_{1} & K n_{1} \\ K T_{2} & K n_{2}\end{array}\right]\left[\begin{array}{c}\Delta T \\ \Delta n\end{array}\right]$, the dipping wavelength change occurs as a result of temperature, and strain change is $\left[\begin{array}{l}\Delta \lambda_{1} \\ \Delta \lambda_{2}\end{array}\right]=$ $\left[\begin{array}{ll}K T_{1} & K \varepsilon_{1} \\ K T_{2} & K \varepsilon_{2}\end{array}\right]\left[\begin{array}{c}\Delta T \\ \Delta \varepsilon\end{array}\right]$, ref. [84].

\subsubsection{Taper with Double Air Cavities}

In this part, the technique concept uses two single-mode fiber air cavities (SMF) produced by femtosecond laser, fusion-splicing, similar to the preceding structures and somewhat tapered methods. A novel tapered fiber method based on fiber MZI with a pair of inner air bubbles is reported. The technique included exposure to the core end face of SMF using femtosecond laser pulses with power calibrated to $1 \mathrm{~mW}$. The results were a nonlinear wavelength shift of $1485 \mathrm{~nm}$ near to where the dip was located and a sensitivity of $28 \mathrm{~nm} / \mathrm{vol}$ [87]. The previous hypothesis presupposes that the length of the exterior cavity is constant regardless of temperature changes. However, the interior air cavity is very tiny, and the fluctuation in it caused by the material's thermal expansion is negligible [88]. The sensitivity can be expressed by Equation (11) [88].

$$
\frac{d \lambda_{v}}{d n_{\text {ext }}}=-\frac{2 L}{2 K+1} \frac{\partial_{c l, m}^{e f f}}{\partial n_{\text {ext }}} /\left[1-\frac{2 L}{2 K+1}\left(\frac{\partial_{\text {core }}^{\text {eff }}}{\partial \lambda}-\frac{\partial_{c l, m}^{e f f}}{\partial \lambda}\right)\right]
$$

where $L$ is the interferometer length, $\partial_{c o r e}^{e f f}$ and $\partial_{c l, m}^{e f f}$ are the effective refractive indices, $n_{\text {ext }}$ is the external refractive index, $\mathrm{k}$ is an integer, and $\lambda_{v}$ is the maximum attenuation wavelength. In the external medium, the optical power is associated with the wave evanescent of the cladding. Consequently, sensitivity is increased by decreasing the fiber diameter of the sensor's contact area with the external medium.

\subsubsection{Taper with Single Air Cavity/Spot}

Several studies have explored the effects of optical taper-based MZI on combining micro holes or microfluidic channels processed by femtosecond laser. The core is combined with higher-order cladding during a single taper exists to narrow down the optical fiber [89]. The MZI is proposed based on a micro spot (microcavity) at a specific distance from the tapered sensor, which is used as a temperature sensor. The results were the refractive index sensitivities of (213.235 and 215.294) nm/RIU [90]. The relationship between the fiber MachZehnder interferometers (FMZI) peak attenuation wavelength of $\delta \lambda_{m, R I}$, and the refractive index (RI) was investigated, as shown in Equation (12), while the relationship of attenuation peak wavelength $\delta \lambda_{m, T}$, and temperature can be expressed as shown in Equation (13) [90]. Moreover, the temperature increase leads to the shifting of the attenuation peak wavelength to achieve a perfect refractive index by considering the temperature impact; the variations in temperature interference orders' peak wavelengths attenuation depend on the inherent cross-sensitivity effects FMZI between the RI and temperature.

$$
\delta \lambda_{m, R I}=\frac{2\left(\Delta n_{e f f, R I}-\delta \lambda_{e f f, R I}\right) L}{2 m+1}-\frac{2 \Delta n_{e f f, R I} L}{2 m+1}=\frac{-2 \delta \lambda_{e f f, R I} L}{2 m+1}
$$




$$
\delta \lambda_{m, T}=\frac{2\left(\Delta n_{e f f, T}-\delta \lambda_{e f f, T}\right) L}{2 m+1}-\frac{2 \Delta n_{e f f, T} L}{2 m+1}=\frac{2 \delta \lambda_{e f f, T} L}{2 m+1}
$$

\subsubsection{Taper with Single Air Cavity/Channel}

Microchannel structure can work as an interferometer method through optical fiber as the spot and a channel for fluids. Yingyu et al. discovered MZI with taper and microchannel. The method used the integration of femtosecond laser with arc fusion splicing for fabrication. The results were sensitivity of $\sim 361.29 \mathrm{~nm} / \mathrm{RIU}$ and RI range from 1.33 to 1.35 [91]. The sensitivity can be enhance by using microchannels/spots (holes) and air cavities with MZIs in a tapered optical fiber to sensing temperature and strain to a certain amount. They can accomplish simultaneous measurement of two parameters. However, the length of MZI is typically longer than necessary, which is harmful to the compactness of the design. However, the size of MZI is sometimes considerable, which detracts from its compactness.

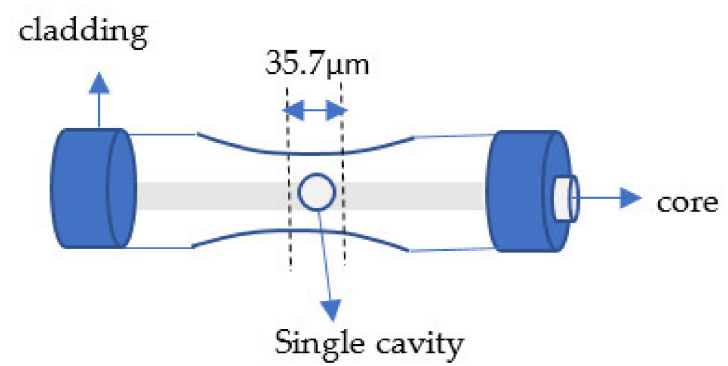

(a)

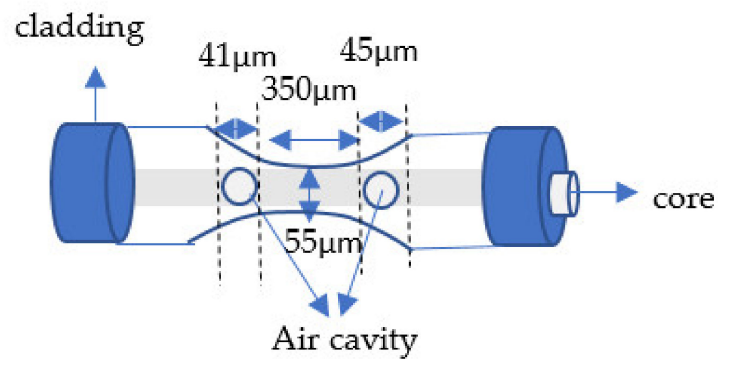

(b)

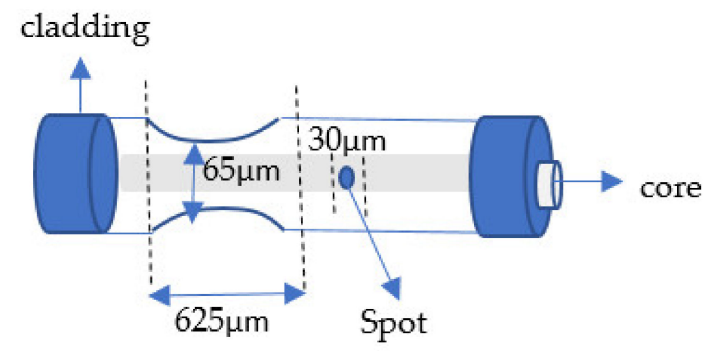

(c)

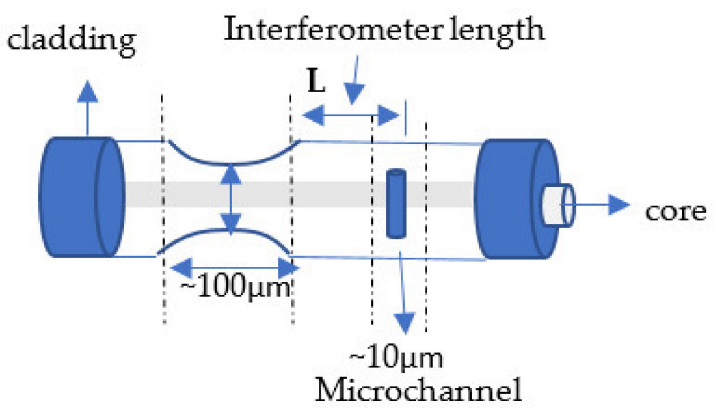

(d)

Figure 5. Tapered fiber based on Mach-Zehnder (MZI) structures. (a) Illustration of tapered based on single cavity [82]. (b) Illustration of tapered based on double air cavities [87]. (c) Illustration of tapered based on air cavity and spot [90]. (d) Illustration tapered based on single air cavity/channel [91].

\subsection{Based on Photonic Crystals Fiber (PCF)}

Initially, PCF was named holes fiber due to air holes in its construction, also known as microstructure fiber, and PCF has two categories: index guiding and photonic band gap. Materials having a photonic band gap (PBG) have features that give them useful nextgeneration photonic device applications $[92,93]$ and can be used to improve a temperatureindependent MZI-based refractometer. This refractometer was built by sandwiching a $29 \mathrm{~mm}$ long, tapered PCF between two standard SMFs. The PCF's air holes completely closed in spliced areas of fusion. This shows that PCF tapering enhanced the sensitivity of the refractometer [94-96], a RI range of 1.3355 to 1.4130 , and a sensitivity of $1529 \mathrm{~nm} /$ RIU. Due to the PCF's extremely low-temperature sensitivity, it was claimed to have a sensitivity 
of $1600 \mathrm{~nm} / \mathrm{RIU}$, approximately eight times that of interferometer not tapered with PCF [97], and it suggested a gas sensor using a nano-beam photonic crystal cavity connected to a tapered optical fiber. The method used seven pairs of tapered air holes, and ten pairs of mirror holes are the nano-beam cavities. A shift in the RI of the gas leads to a linear change in the resonance wavelength, with a sensitivity attributed to the gas of around $0.19 \mathrm{~nm} / 10^{-3} \mathrm{RIU}$ [98]. The construction of photonic crystals with a linearly tapered waveguide is suggested to gradually vary the waveguide width. Four drop channels are supplied to enable applications such as wavelength de-multiplexing, and waveguide has been tapered to confine the propagating light to the required locations [99]. Figure 6 shows tapered fiber based on photonic crystals fiber (PCF).

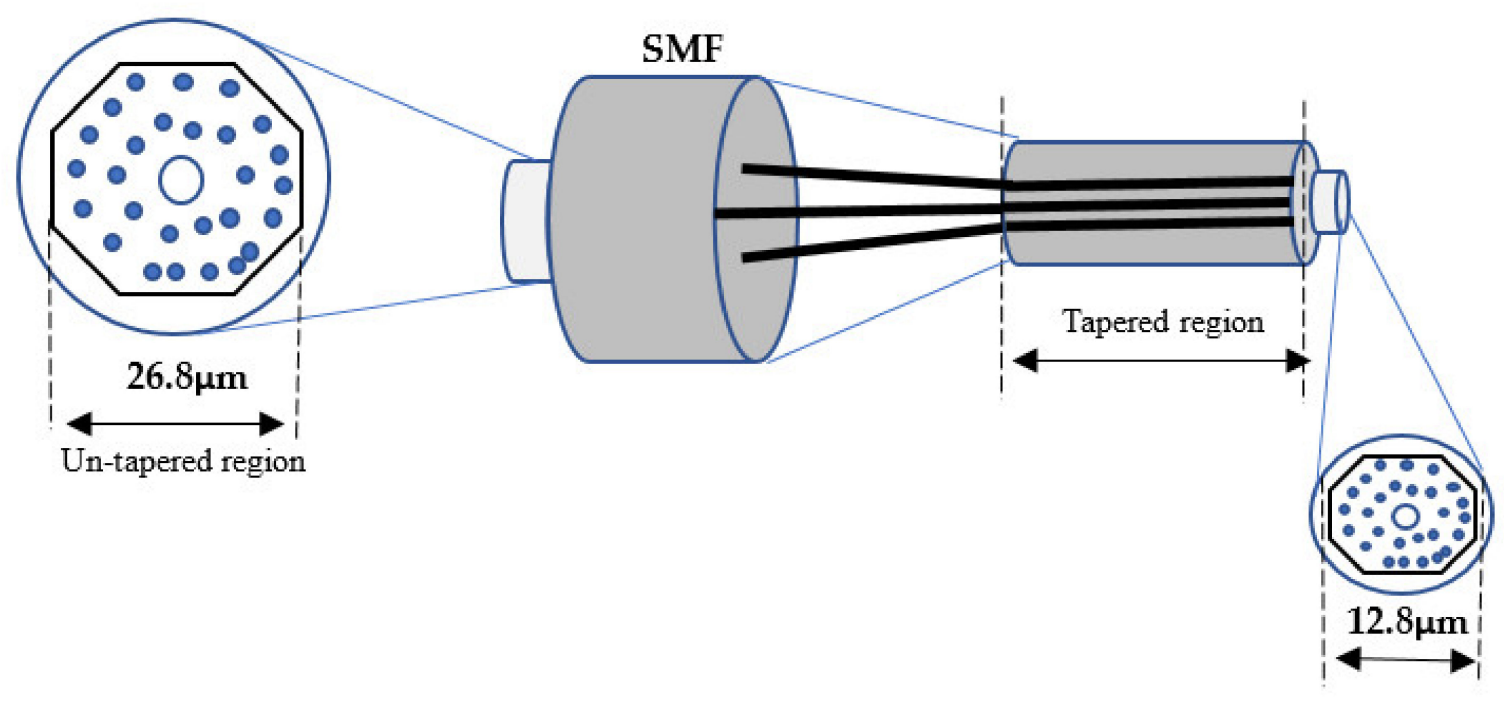

Figure 6. Tapered fiber based on photonic crystals fiber (PCF) [94].

\subsection{Based on Surface Plasmon Resonance (SPR)}

Surface plasmon resonance (SPR) is a very effective instrument widely utilized in chemical, biological, and medical applications. It is a type of refractometric sensing device that measures refractive index (RI) changes in the field. The coupling medium via the contact is required for photon energy excitation. It can do so by utilizing the optical system's form structures, such as prism coupling (a method known as the Kretschmann design), localized surface plasmon (LSPR), waveguide, fiber-optic, and grating structures [100-104]. Equation (14) illustrates the resonance condition required for SPR:

$$
\sqrt{\varepsilon_{p}} \sin \theta_{r e s}=\sqrt{\frac{\varepsilon_{m} \varepsilon_{d}}{\varepsilon_{m}+\varepsilon_{d}}}
$$

where $\varepsilon_{p}, \varepsilon_{m}$, and $\varepsilon_{d}$ denote the dielectric constants of the substrate (prism, optical fiber backbone, etc.), a plasmonic material (metals), and a dielectric layer (analyte medium), respectively, and $\theta_{\text {res }}$ denotes the incident resonance angle. The optical tapered fiber-based SPR configuration where a taper is coated with a thin metal film has several advantages over the standard SPR configuration, including its small size, light weight, and automatic alignment sacrificing sensitivity or overall sensor performance. Label-free surface plasmon resonance (SPR) sensor based on a tapered fiber is used in biochemical diagnosis. The sensing method examines the change in transmission intensity caused by deposited gold nanoparticles on the tapered fiber surface owing to evanescent field absorption $[105,106]$, as shown in Figure 7. 


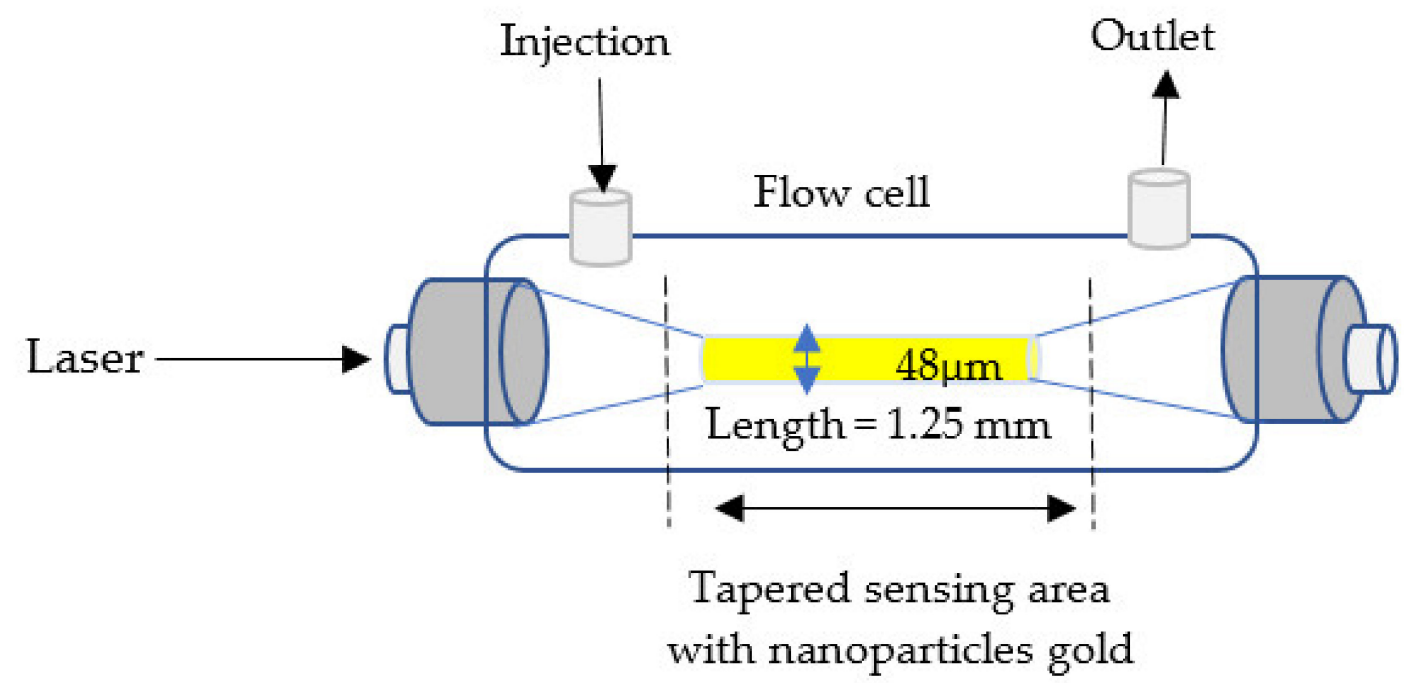

Figure 7. Tapered fiber optic based on surface plasmonic resonance (SPR) [105].

\subsection{Based on Multi-Taper Devices}

In this section, a multi-mode interference (MMI) device has been thoroughly described in a planar waveguide. Typically, these properties become useful at self-imaging of the light input field, a well-established technique commonly used in the design of optical communications beam splitters, combiners, and multiplexers $[107,108]$. The authors suggested a refractive index (RI) sensor structure based on multi-tapered by using single-mode/multi-mode fibers. The tapered area generates the evanescent wave, which penetrates the surrounding liquid. The methodology used was manufacturing three, five, and eight tapers, and the results were RI sensitivity of $261.9 \mathrm{~nm} / \mathrm{RIU}$ in the RI range of 1.3333-1.3737 [109]. In another report, the fiber refractometer is illustrated using MMF sandwiched between two SMF half-tapers. At an external RI of 1.333, the produced interference fringe moves toward longer wavelengths with a $319.3 \mathrm{~nm} / \mathrm{RIU}$ response sensitivity. The response sensitivity increases monotonically to $500.6 \mathrm{~nm} / \mathrm{RIU}$ as the RI operates from 1.333 to 1.411 [110]. The researchers proposed a new intensity-modulated RI sensor based on a single-mode-single-mode (FT-SMS) fiber structure. The front taper is produced using a flame-heated technique on MMF. The beam propagation method is utilized to investigate the taper region intensity feature, and comprehensive RI and temperature testing are then performed. According to the experimental results, the sensitivity is $342.815 \mathrm{~dB} / \mathrm{RIU}$, between 1.33 and 1.37. The equivalent resolution is $2.92 \times 10^{5} \mathrm{RIU}$, about four times that of wavelength demodulation [111], as shown in Figure 8.

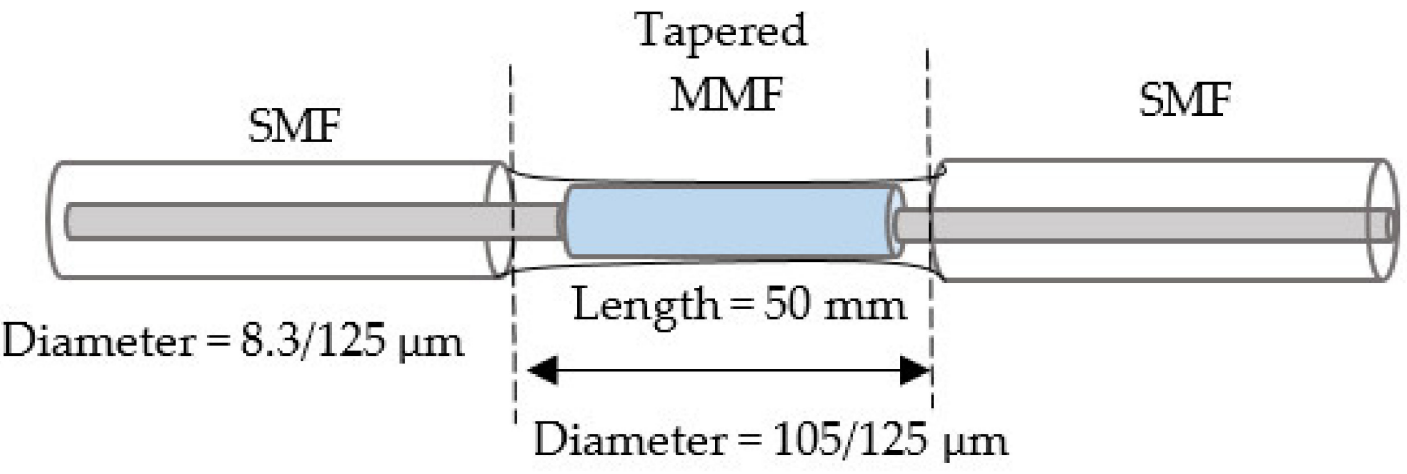

Figure 8. Tapered fiber optic based on multi-taper devices [108]. 


\subsection{Based on Fiber Loop Ring-Down (FLRD) Technology}

FLRD is a sensitive absorption method in which the rate of absorption in an optical cavity is measured. The effective absorption path length is very long. In addition, the sensitivity independent of the intensity of light source fluctuations [112]. A study of a constructed RI sensor based on tapered fiber loop ring-down (FLRD) was described, and the ring-down contributed to time changes with the intensity loss near the tapered SMF. Results indicated a sensitivity of 388.581 RIU and a detection limit of less than $2.57 \times 10^{5} \mathrm{RIU}$ [113]. A fiber-optic sensor with an S fiber taper (SFT) structure is presented. The SFT is used in line with MZI and is placed into a compensating fiber loop for the aim of evaluating the RI by improving the fiber loop properties. The surrounding refractive index may be readily determined by querying the fiber loop's ring-down time. Results show a sensitivity of $3128.954 \mu \mathrm{s} / \mathrm{RIU}$ during a range of 1.3330-1.3682 [114]. A new refractive index sensing technique based on the chaotic association FLRD method is suggested. The results show that the sensitivity improves as an inverse relationship with a decrease in the loop length. Furthermore, the loop length has a minor effect on the system detection limit of $10^{4}$ RIU [115], as shown in Figure 9.

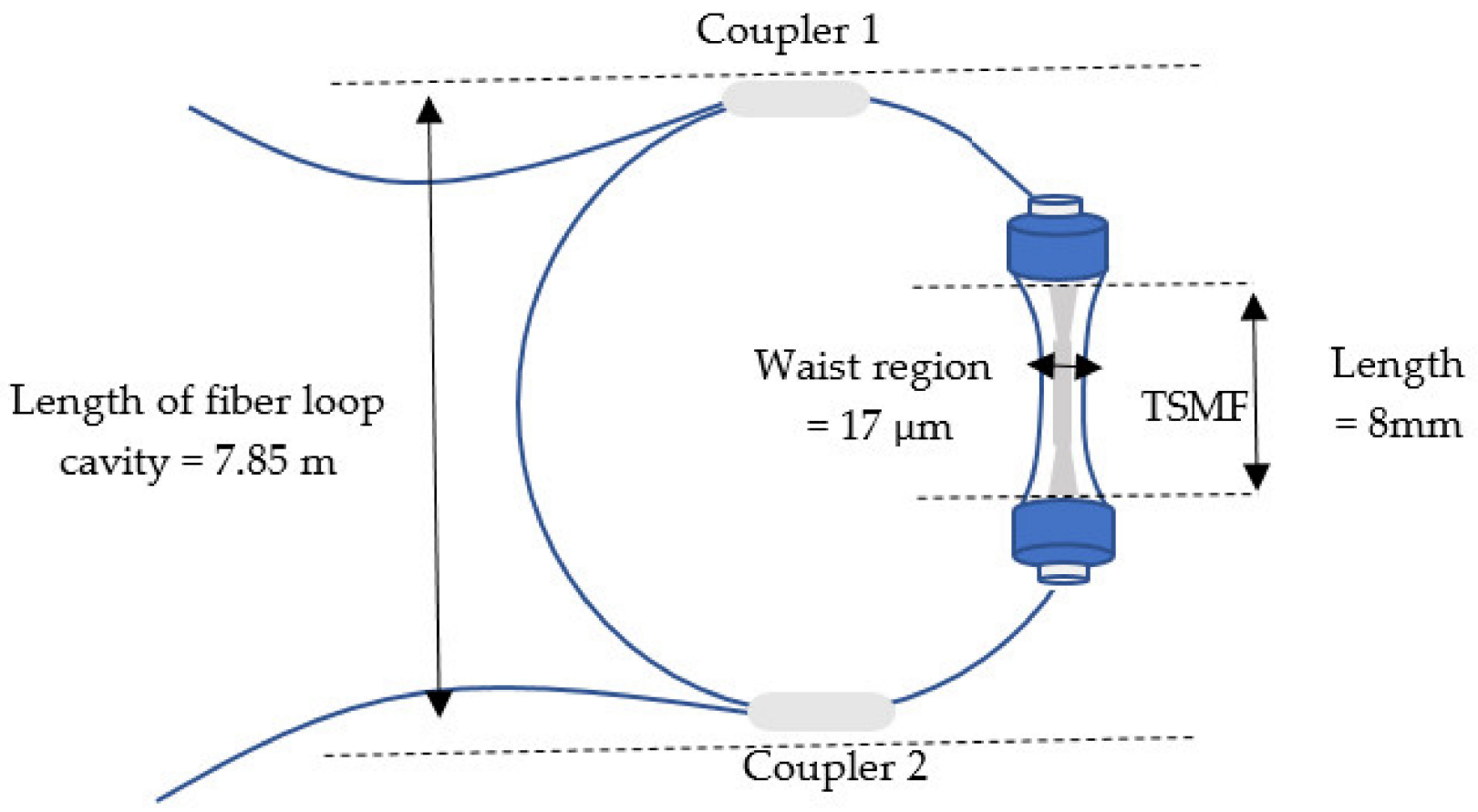

Figure 9. Tapered fiber optic based on fiber loop ring-down (FLRD) [115].

\subsection{Based on Optical Tweezers}

Optical tweezer tools are commonly applied for many fields of application, such as biological, genetic, neurosciences, molecular medicine, pharmacy, and biotechnology. They are used for manipulating microscopic objectives, such as cells and bacteria, by focusing light beams (intensity maximum occurs) on nanoparticles. Due to their ease of manipulation, narrow shape, and ease of manufacture, optical fiber tweezers have garnered substantial attention in optical trapping in recent years [116-118]. A pair of SMF tweezers for biomedical use and multi-trapping research was presented. The trapping force feature of this pair of SMF tweezers is computed using the finite time-domain method. Results demonstrate that the number of particles trapped is related to refractive index and particle size [119-121]. Combining 3D-printed Fresnel lenses with a dual fiber surface is a good approach for increasing trapping efficiency and stability in the optical tweezer method. In dual-fiber traps, the use of a converging beam rather than a diverging beam results in a high trapping efficiency in both the axial and transverse directions. Diffractive Fresnel 
lenses connect beams with a numerical aperture of up to 0.7 . These lenses give a long focus distance of up to $200 \mathrm{~m}$ in a medium with a relatively high refractive index. Femtosecond two-photon lithography enables the fabrication of such diffractive lenses with microscale features at the fiber tip [122], as shown in Figure 10.

\section{Tapered area}

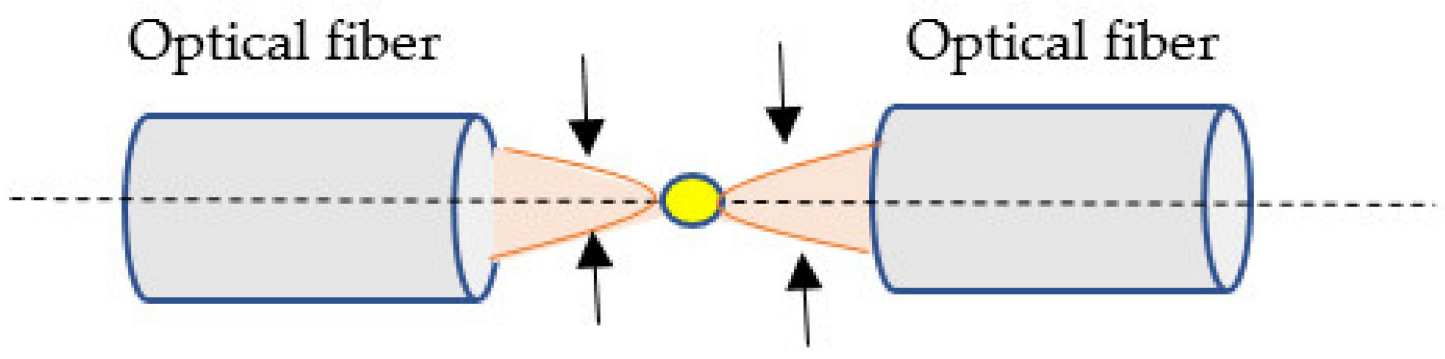

a. Dual fiber optical tweezers

\section{Optical fiber}

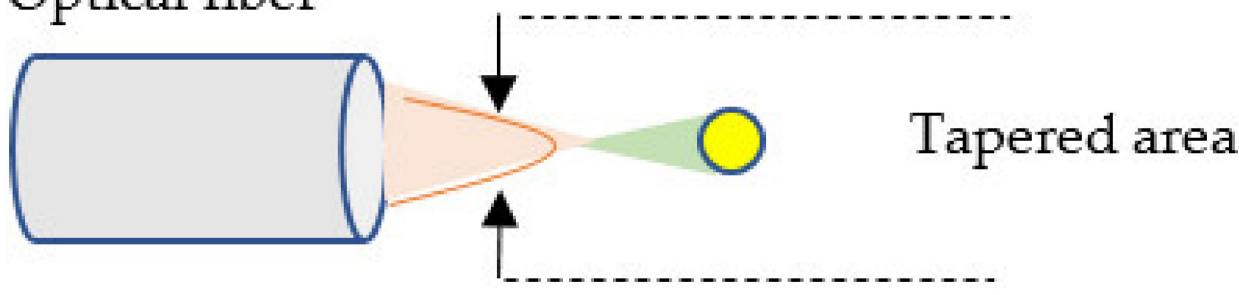

b. Single fiber optical tweezers

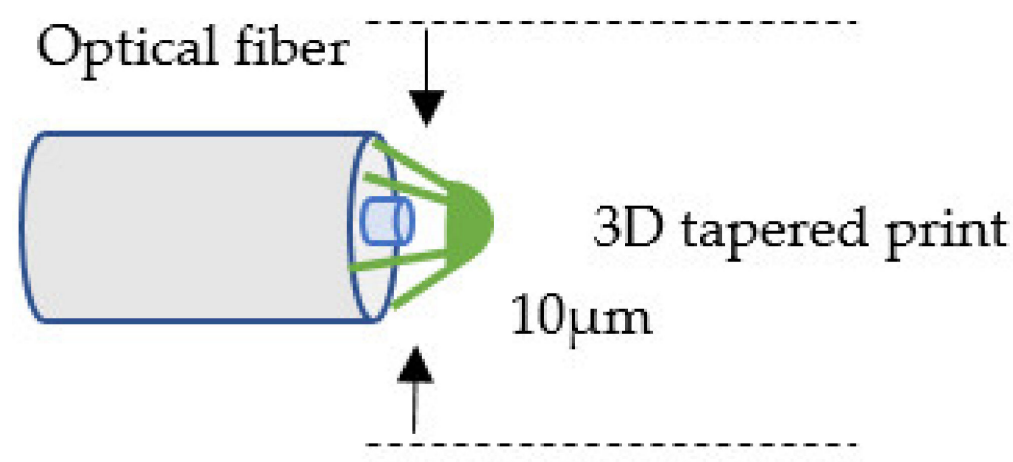

c. 3D tapered optical tweezers

Figure 10. Tapered fiber optic based on optical tweezer structures [122]. 
Table 1. Studies analysis for categorizes tapered-fiber forms.

\begin{tabular}{|c|c|c|c|c|c|c|c|c|}
\hline \multirow{2}{*}{$\begin{array}{l}\text { Tapered } \\
\text { Method }\end{array}$} & \multirow{2}{*}{$\begin{array}{l}\text { Taper } \\
\text { Length }\end{array}$} & \multirow{2}{*}{ Sensitivity } & \multirow{2}{*}{$\begin{array}{c}\text { RI Scale OR } \\
\text { Wavelength Scale }\end{array}$} & \multirow{2}{*}{$\begin{array}{c}\text { Waist } \\
\text { Diameter }\end{array}$} & \multicolumn{2}{|c|}{ Publishing } & \multirow{2}{*}{ Application } & \multirow{2}{*}{ Ref } \\
\hline & & & & & Quantity & Quality & & \\
\hline FBG & $100 \mu \mathrm{m}$ & $\begin{array}{c}0.90,-38.49 \mathrm{pm} / \mathrm{MPa} \\
12.03 \mathrm{pm} /{ }^{\circ} \mathrm{C}\end{array}$ & $0.7250,0.9980$ & $30 \mu \mathrm{m}$ & $\sqrt{ }$ & $\sqrt{ }$ & $\begin{array}{l}\text { Temperature and } \\
\text { pressure }\end{array}$ & [64] \\
\hline FBG & $10 \mathrm{~mm}$ & $\begin{array}{l}1129.44 \mathrm{pm} / \mu \varepsilon \\
-54.58 \mathrm{pm} /{ }^{\circ} \mathrm{C}\end{array}$ & NA & $90 \mu \mathrm{m}$ & $\sqrt{ }$ & $\sqrt{ }$ & $\begin{array}{c}\text { Temperature and } \\
\text { strain }\end{array}$ & [70] \\
\hline FBG & $\begin{array}{l}800 \mu \mathrm{m} \\
750 \mu \mathrm{m}\end{array}$ & $\begin{array}{l}459.974 \mathrm{~nm} / \text { RIU } \\
420.781 \mathrm{~nm} / \text { RIU }\end{array}$ & $1.3540-1.3810$ & $60 \mu \mathrm{m}$ & $\times$ & $\sqrt{ }$ & $\begin{array}{l}\text { Biological, medical, } \\
\text { and chemical }\end{array}$ & [63] \\
\hline FBG & $780 \mu \mathrm{m}$ & $269.76 \mathrm{~dB} / \mathrm{RIU}$ & $1.3330-1.4060$ & $54 \mu \mathrm{m}$ & $\times$ & $\sqrt{ }$ & Temperature & [62] \\
\hline LPFG & $619.24 \mu \mathrm{m}$ & $\begin{array}{c}45.87 \mathrm{pm} /{ }^{\circ} \mathrm{C} \\
-52.57 \mathrm{~nm} / \mathrm{RIU}\end{array}$ & $1.33-1.37$ & $44.81 \mu \mathrm{m}$ & $x$ & $\sqrt{ }$ & Temperature & [73] \\
\hline LPFG & $730 \mu \mathrm{m}$ & 8188 nm/RIU & $1.33-1.34$ & $12 \mu \mathrm{m}$ & $x$ & $\sqrt{ }$ & $\begin{array}{c}\text { Biological and } \\
\text { chemical }\end{array}$ & [75] \\
\hline MZI & $\sim 35.7 \mu \mathrm{m}$ & $\begin{array}{l}\sim 8239 \mathrm{pm} / \mathrm{MPa} \\
0.0055 \mathrm{MPa} /{ }^{\circ} \mathrm{C}\end{array}$ & $1.3241-1.3280$ & $24 \mu \mathrm{m}$ & $\sqrt{ }$ & $\sqrt{ }$ & $\begin{array}{l}\text { Temperature and } \\
\text { pressure }\end{array}$ & [82] \\
\hline MZI & $\begin{array}{l}350 \mu \mathrm{m} \\
200 \mu \mathrm{m}\end{array}$ & $28 \mathrm{~nm} / \mathrm{vol}$ & 1.3645 & $55 \mu \mathrm{m}$ & $\times$ & $\sqrt{ }$ & $\begin{array}{l}\text { Ethanol } \\
\text { concentration }\end{array}$ & [87] \\
\hline MZI & $625 \mathrm{~mm}$ & $\begin{array}{c}213.235-215.294 \\
\mathrm{~nm} / \mathrm{RIU} \\
0.089 \text { and } 0.094 \mathrm{~nm} /{ }^{\circ} \mathrm{C}\end{array}$ & 0.089 & $65 \mathrm{~mm}$ & $\times$ & $\times$ & Temperature & [90] \\
\hline LPFG & $\begin{array}{l}2.3 \mathrm{~mm} \\
2.5 \mathrm{~mm}\end{array}$ & $\begin{array}{c}1.82 \mathrm{pm} / \mu \varepsilon-8.17 \\
\mathrm{pm} / \mu \varepsilon \\
47.9 \mathrm{pm} /{ }^{\circ} \mathrm{C} \text { and } \\
65 \mathrm{pm} /{ }^{\circ} \mathrm{C}\end{array}$ & $\begin{array}{c}\text { Wavelength } \\
\text { shifting } 1539.4 \mathrm{~nm} \\
\text { to } 1541.2 \mathrm{~nm},\end{array}$ & $62.5 \mathrm{~mm}$ & $x$ & $\times$ & $\begin{array}{l}\text { Temperature and } \\
\text { strain }\end{array}$ & [76] \\
\hline MZI & $4 \mathrm{~mm}$ & $\begin{array}{c}\sim 4202 \mathrm{~nm} / \mathrm{RIU} \\
41 \mathrm{pm} /{ }^{\circ} \mathrm{C}\end{array}$ & $1.3241-1.3280$ & $\begin{array}{l}95 \mu \mathrm{m} \\
60 \mu \mathrm{m}\end{array}$ & $\sqrt{ }$ & $\sqrt{ }$ & Temperature & [85] \\
\hline SPR & $1.25 \mathrm{~mm}$ & $3.2 \times 10^{5} \mathrm{RIU}$ & $1.333-1.403$ & $48 \mu \mathrm{m}$ & $\times$ & $\sqrt{ }$ & $\begin{array}{l}\text { Biochemical and } \\
\text { biomolecular }\end{array}$ & [105] \\
\hline SPR & $25 \mathrm{~mm}$ & $18 \mathrm{~nm} / \mathrm{RIU}$ & $1.3324-1.4254$ & $15 \mu \mathrm{m}$ & $\times$ & $x$ & $\begin{array}{l}\text { Biological and } \\
\text { chemical }\end{array}$ & [106] \\
\hline PCF & $\sim 2 \mathrm{~cm}$ & $1600 \mathrm{~nm} / \mathrm{RIU}$ & $1.3333-1.3577$ & $\begin{array}{l}61 \mu \mathrm{m} \text { top } \\
49 \mu \mathrm{m} \text { mid } \\
30 \mu \mathrm{m} \\
\text { bottom }\end{array}$ & $\sqrt{ }$ & $\sqrt{ }$ & $\begin{array}{l}\text { Biochemical and } \\
\text { biomolecular }\end{array}$ & [96] \\
\hline PCF & $29 \mathrm{~mm}$ & $1529 \mathrm{~nm} / \mathrm{RIU}$ & $1.3355-1.413$ & $71.7 \mu \mathrm{m}$ & $\sqrt{ }$ & $\sqrt{ }$ & $\begin{array}{l}\text { Environments, } \\
\text { biomolecules }\end{array}$ & [97] \\
\hline Multi- devices & $550 \mu \mathrm{m}$ & $261.9 \mathrm{~nm} / \mathrm{RIU}$ & $1.3333-1.3737$ & $52 \mu \mathrm{m}$ & $\sqrt{ }$ & $\sqrt{ }$ & $\begin{array}{l}\text { Biological and } \\
\text { chemical }\end{array}$ & [109] \\
\hline Multi- devices & $17.8 \mathrm{~mm}$ & $-342.815 \mathrm{~dB} / \mathrm{RIU}$ & $1.33-1.37$ & $29.2 \mu \mathrm{m}$ & $\sqrt{ }$ & $\sqrt{ }$ & $\begin{array}{l}\text { Biochemical and } \\
\text { environments }\end{array}$ & [111] \\
\hline $\begin{array}{l}\text { Loop } \\
\text { ring-down }\end{array}$ & $8 \mathrm{~mm}$ & $0.045 \mathrm{~ns}^{-1} \mathrm{RIU}^{-1}$ & $1.3347-1.3721$ & $17 \mu \mathrm{m}$ & $\sqrt{ }$ & $\sqrt{ }$ & $\begin{array}{c}\text { Medical } \\
\text { pharmaceuticals, } \\
\text { industrial fluids, } \\
\text { photochemical } \\
\text { plastics, and food } \\
\text { industry }\end{array}$ & [115] \\
\hline $\begin{array}{l}\text { Loop } \\
\text { ring-down }\end{array}$ & $795 \mu \mathrm{m}$ & $-3128.954 \mu \mathrm{s} / \mathrm{RIU}$ & $3330-1.3682$ & $65 \mu \mathrm{m}$ & $\sqrt{ }$ & $\sqrt{ }$ & Biochemistry & [114] \\
\hline $\begin{array}{l}\text { Loop } \\
\text { ring-down }\end{array}$ & $782 \mu \mathrm{m}$ & $-388.581 \mu \mathrm{s} / \mathrm{RIU}$ & $1.335-1.375$ & $28 \mu \mathrm{m}$ & $\sqrt{ }$ & $\sqrt{ }$ & $\begin{array}{c}\text { Industrial processing } \\
\text { and } \\
\text { bio/chemical }\end{array}$ & [113] \\
\hline Multi- devices & $3 \mathrm{~mm}$ & $\begin{array}{l}500.6 \mathrm{~nm} / \mathrm{RIU} \\
319.3 \mathrm{~nm} / \mathrm{RIU}\end{array}$ & 1.333 to 1.411 & $17 \mu \mathrm{m}$ & $\sqrt{ }$ & $\sqrt{ }$ & $\begin{array}{l}\text { Chemical and } \\
\text { biological }\end{array}$ & [110] \\
\hline $\begin{array}{l}\text { Optical } \\
\text { tweezer }\end{array}$ & $\begin{array}{l}200 \mu \mathrm{m} \\
380 \mu \mathrm{m}\end{array}$ & NA & NA & $\begin{array}{c}1 \mu \mathrm{m} \\
3.3 \mu \mathrm{m}\end{array}$ & $\sqrt{ }$ & $\sqrt{ }$ & $\begin{array}{l}\text { Particle and } \\
\text { single-cell } \\
\text { microscopy }\end{array}$ & [122] \\
\hline $\begin{array}{l}\text { Optical } \\
\text { tweezer }\end{array}$ & $20 \mu \mathrm{m}$ & NA & $1.33-1.40$ & $\begin{array}{l}2.5 \mu \mathrm{m} \\
3.7 \mu \mathrm{m}\end{array}$ & $\times$ & $x$ & Biomedical & [119] \\
\hline
\end{tabular}

\section{Opportunities and Challenges}

One of the main problems for future applications of tapered optical fiber sensors is manufacturing the devices, which must be dependable and reproducible. As we know, taper devices are not selectively sensitive in their most basic form and require specificityenhancing coating. Furthermore, there are difficulties in handling such as packing and mechanical strength. In addition, the limit of diffraction is the essential restriction to 
trapping. It is difficult to confine particles inside the diffraction limit, with limited distance around the trapped particle. The limit of diffraction also makes it challenging to combine additional manipulation and measurement activities that must be concurrent [123] and to achieve excellent symmetry while avoiding the volatility of the waist diameter induced by flame turbulence [124-127]. Due to the tiny size of the fiber core, the communication fiber connector demands extreme accuracy. The influence of lateral displacement on the coupling effectiveness of fiber connectors was reported. The innovative directional tapered description optical fiber connection is then constructed, considering that optical fiber is often used in pairs. One is utilized for transmission and the other for reception. The direction of signal transmission tapers the redesigned connector fiber head construction [128,129]. Moreover, the future opportunities to advance (micro/nano) techniques and develop fibers with unique optical characteristics require little question that designs and fabrications of innovative microstructured optical sensors will continue to be a growing research field. The proposed development of microstructured fiber optic sensors will face both challenges and possibilities [41], for example, optical fiber potential sensing selectivity with the dual-parameter measuring capability to date. However, there are requirements to reduce the error of multi-parameter measurements and expand the dual-parameter size to three-parameter or over. In addition, there is higher sensitivity because more accurate measurements in chemical and biological sectors single-molecule identification and gas sensing are desired. Chemical and biological single molecule identification and gas sensing can be an intelligent and flexible sensor design with varied target samples and different conditions. Long stability and the robustness of the small structures are critical to sensing effectiveness and longevity devices. Finally, optical fiber has many essential features such as flexible input/output, capability, and light delivery for remote instruments. Consequently, optical tapering might apply for on-site analytics and portable mini-spectrometers. Table 2 summarizes the challenges of tapered fiber structures.

Table 2. Shows the challenges of tapered fiber techniques.

\begin{tabular}{|c|c|}
\hline Tapered Method & Challenges \\
\hline Fiber Bragg grating (FBG) & $\begin{array}{l}\text { - Some spectra of reflection overlapped. } \\
\text { - Unstable interference wave. } \\
\text { - Complex configuration for grating inscription. } \\
\text { - Insufficient sensitivity. }\end{array}$ \\
\hline $\begin{array}{l}\text { Long-period fiber grating } \\
\text { (LPFG) }\end{array}$ & $\begin{array}{l}\text { - The spectrum is limiting. } \\
\text { - Cross-sensitivity problem. } \\
\text { - The roughness of the surface. }\end{array}$ \\
\hline Mach-Zehnder (MZI) & $\begin{array}{l}\text { - Spectral band-width is limited. } \\
\text { - Manufacturing cost. } \\
\text { - Sensitivity enhancement is required. }\end{array}$ \\
\hline Photonic crystals (PC) & $\begin{array}{l}\text { - The samples given are limited. } \\
\text { - The manufacturing of metal layers is a complex procedure. } \\
\text { - Integration is expensive. } \\
\text { - Mechanical reliability is weak, and mass production is challenging. }\end{array}$ \\
\hline $\begin{array}{l}\text { Surface plasmon resonance } \\
\text { (SPR) }\end{array}$ & $\begin{array}{l}\text { - The life of the sensitive layer controls the lifetime of the device. } \\
\text { - Small sample size. } \\
\text { - There is a need for practical application, including different sample } \\
\text { collection processes. } \\
\text { - The waist area is rather hard. }\end{array}$ \\
\hline Multi-taper devices & $\begin{array}{l}\text { - } \text { Measured refractive index range is limited. } \\
\text { - } \text { Limited stability. } \\
\text { - The roughness of the surface. }\end{array}$ \\
\hline $\begin{array}{l}\text { Fiber loop ring-down } \\
\text { technology }\end{array}$ & $\begin{array}{l}\text { - The samples given are limited. } \\
\text { - Measuring accuracy depends on the high wavelength resolution of the } \\
\text { de-modulation device. }\end{array}$ \\
\hline Optical tweezers & $\begin{array}{l}\text { - Obtain an analytical formula for the output light field is difficult. } \\
\text { - The trapping of optical tweezers is inadequate due to the limit of laser } \\
\text { beam diffraction. } \\
\text { - Dramatic disruptions from molecular diffusion. }\end{array}$ \\
\hline
\end{tabular}




\section{Conclusions}

In summary, this narrative review evaluated many types of common tapered fiber structures in different optical sensors forms and their respective concepts and applications, besides their theoretical, manufacturing techniques, and features. Furthermore, tapered fiber could be designed as sensors for various measurands, including sensors for RI, temperature, humidity, and bio-sensing, have been considered. In addition, this review also assesses the effects of the length and waist optical taper for improving the sensitivity. As a result, they provide more freedom in producing focusers with unique spot sizes. Therefore, tapered fiber can be potentially the most effective in medicinal and environmental applications. Finally, this analysis provides a road map of fundamental scientific primer for better understanding on the difficulties and implementation to improve optical sensors in this field.

Author Contributions: B.A.T. drafted the original manuscript; Y.A.M., conceptualization and methodology; N.A. (Norazida Ali) supervised and validated the work with the help of N.A. (Norhana Arsad), N.M.S., M.M.F., R.M.M.Y. and N.N.B. All authors have read and agreed to the published version of the manuscript.

Funding: Universiti Kebangsaan Malaysia (UKM) funded this study through grant numbers (IF0419IF1082 and MI-2020-001).

Institutional Review Board Statement: Not applicable.

Informed Consent Statement: Not applicable.

Data Availability Statement: Not applicable.

Acknowledgments: The authors gratefully acknowledge the financial support of the Department of Electrical, Electronic and Systems Engineering/Faculty of Engineering and Built Environment/Universiti Kebangsaan Malaysia (UKM) for their encouragement and grant support (IF0419IF1082 and MI-2020-001).

Conflicts of Interest: The authors declare no conflict of interest.

\section{References}

1. Newton, J. Wellbeing and the Natural Environment: A Brief Overview of the Evidence; University of Bath: Bath, UK, $2007 ;$ pp. 1-53.

2. Joe, H.E.; Yun, H.; Jo, S.H.; Jun, M.B.G.; Min, B.K. A review on optical fiber sensors for environmental monitoring. Int. J. Precis. Eng. Manuf. Green Technol. 2018, 5, 173-191. [CrossRef]

3. Song, H.; Pei, H.; Zhu, H. Monitoring of tunnel excavation based on the fiber Bragg grating sensing technology. Meas. J. Int. Meas. Confed. 2021, 169, 108334. [CrossRef]

4. Guo, X.; Wang, B.; Wang, Z.; Yu, W.; Ma, Z.; Yang, T. Application of the Microclamped Fiber Bragg Grating (FBG) Sensor in Rock Bolt Support Quality Monitoring. Adv. Civ. Eng. 2020, 2020. [CrossRef]

5. Sahota, J.K.; Gupta, N.; Dhawan, D. Fiber Bragg grating sensors for monitoring of physical parameters: A comprehensive review. Opt. Eng. 2020, 59, 1. [CrossRef]

6. Wang, J.N.; Luo, C.Y. Long-period fiber grating sensors for the measurement of liquid level and fluid-flow velocity. Sensors 2012, 12, 4578-4593. [CrossRef]

7. Bandyopadhyay, S.; Biswas, P.; Chiavaioli, F.; Dey, T.K.; Basumallick, N.; Trono, C.; Giannetti, A.; Tombelli, S.; Baldini, F.; Bandyopadhyay, S. Long-period fiber grating: A specific design for biosensing applications. Appl. Opt. 2017, 56, 9846. [CrossRef] [PubMed]

8. Zhao, X.W.; Wang, Q. Mini review: Recent advances in long period fiber grating biological and chemical sensors. Instrum. Sci. Technol. 2019, 47, 140-169. [CrossRef]

9. Saghaei, H.; Elyasi, P.; Karimzadeh, R. Design, fabrication, and characterization of Mach-Zehnder interferometers. Photonics Nanostruct. Fundam. Appl. 2019, 37, 100733. [CrossRef]

10. El Shamy, R.S.; Khalil, D.; Swillam, M.A. Mid Infrared Optical Gas Sensor Using Plasmonic Mach-Zehnder Interferometer. Sci. Rep. 2020, 10, 1-9. [CrossRef]

11. Inan, H.; Poyraz, M.; Inci, F.; Lifson, M.A.; Baday, M.; Cunningham, B.T.; Demirci, U. Photonic crystals: Emerging biosensors and their promise for point-of-care applications. Chem. Soc. Rev. 2017, 46, 366-388. [CrossRef]

12. Long, H.; Bao, L.; Habeeb, A.A.; Lu, P. Effects of doping concentration on the surface plasmonic resonances and optical nonlinearities in AGZO nano-triangle arrays. Opt. Quantum Electron. 2017, 49, 1-8. [CrossRef]

13. Zhou, J.; Qi, Q.; Wang, C.; Qian, Y.; Liu, G.; Wang, Y.; Fu, L. Surface plasmon resonance (SPR) biosensors for food allergen detection in food matrices. Biosens. Bioelectron. 2019, 142, 111449. [CrossRef] 
14. Salam, A.O.A.; Sheriff, R.E.; Al-Araji, S.R.; Mezher, K.; Nasir, Q. Multi-taper spectrum-based estimator for cognitive radio using multiple antennas and STBC techniques. IET Circ. Dev. Syst. 2018, 12, 133-143. [CrossRef]

15. Chen, Y.; Liu, T.; Han, Q.; Yan, W.; Yu, L. Fiber loop ring-down cavity integrated U-bent single-mode-fiber for magnetic field sensing. Photonics Res. 2016, 4, 322. [CrossRef]

16. Yang, Y.; Yang, L.; Zhang, Z.; Yang, J.; Wang, J.; Zhang, L.; Deng, X.; Zhang, Z. Fiber loop ring down for static ice pressure detection. Opt. Fiber Technol. 2017, 36, 312-316. [CrossRef]

17. Killian, J.L.; Ye, F.; Wang, M.D. Optical Tweezers: A Force to Be Reckoned With. Cell 2018, 175, 1445-1448. [CrossRef]

18. Crozier, K.B. Quo vadis, plasmonic optical tweezers? Light Sci. Appl. 2019, 8, 4-9. [CrossRef]

19. Kao, K.C.; Hockham, G.A. Dielectric-Fibre Surface Waveguides for Optical Frequencies; Pergamon Press Ltd.: Oxford, UK, 1966.

20. Culshaw, B. Optical Fiber Sensor Technologies: Opportunities and-Perhaps-Pitfalls. J. Lightwave Technol. 2004, 22, 39-50. [CrossRef]

21. Taha, B.A.; Mashhadany, Y.A.; Mokhtar, M.H.H.; Zan, M.S.D.B.; Arsad, N. An analysis review of detection coronavirus disease 2019 (COVID-19) based on biosensor application. Sensors 2020, 20, 6764. [CrossRef] [PubMed]

22. Taha, B.A. Perspectives of Photonics Technology to Diagnosis COVID-19 Viruses: A Short Review. J. Appl. Sci. Nanotechnol. 2021, 1, 1-6. [CrossRef]

23. Taha, B.A.; Al Mashhadany, Y.; Bachok, N.N.; Bakar, A.A.A.; Mokhtar, M.H.H.; Zan, M.S.D.B.; Arsad, N. Detection of COVID-19 Virus on Surfaces Using Photonics: Challenges and Perspectives. Diagnostics 2021, 11, 1119. [CrossRef] [PubMed]

24. Elgaud, M.M.; Bakar, A.A.A.; Ghaith, A.A.; Naim, N.F.; Arsad, N.; Mokhtar, M.H.H.; Azeman, N.H.; Zan, M.S.D. Pulse compressed time domain multiplexed fiber bragg grating sensor: A comparative study. IEEE Access 2018, 6, 64427-64434. [CrossRef]

25. Rao, Y.-J.; Deng, M.; Duan, D.-W.; Yang, X.-C.; Zhu, T.; Cheng, G.-H. Micro Fabry-Perot interferometers in silica fibers machined by femtosecond laser. Opt. Express 2007, 15, 14123. [CrossRef] [PubMed]

26. Fernandes, L.A.; Grenier, J.R.; Herman, P.R.; Aitchison, J.S.; Marques, P.V.S. Femtosecond laser fabrication of birefringent directional couplers as polarization beam splitters in fused silica. Opt. Express 2011, 19, 11992. [CrossRef]

27. Jung, Y.; Lee, S.; Lee, B.H.; Oh, K. Ultracompact in-line broadband Mach-Zehnder interferometer using a composite leaky hollow-optical-fiber waveguide. Opt. Lett. 2008, 33, 2934-2936. [CrossRef]

28. Leng, Y.; Yun, V.E.; Goldhar, J. UV laser fabrication and modification of fiber Bragg gratings by stitching sub-gratings with in situ fluorescence monitoring. Appl. Opt. 2017, 56, 6977-6981. [CrossRef]

29. Morales, A.M.; Lieber, C.M. A laser ablation method for the synthesis of crystalline semiconductor nanowires. Science 1998, 279, 208-211. [CrossRef]

30. Westwater, J. Growth of silicon nanowires via gold/silane vapor-liquid-solid reaction. J. Vac. Sci. Technol. B Microelectron. Nanometer Struct. 1997, 15, 554. [CrossRef]

31. Chen, J.; Reed, M.A.; Rawlett, A.M.; Tour, J.M. Large on-off ratios and negative differential resistance in a molecular electronic device. Science 1999, 286, 1550-1552. [CrossRef]

32. Giallorenzi, T.G.; Dandridge, A. Optical Fiber Sensor Technology. IEEE Trans. Microwave Theory Tech. 1982, 30, 472-511. [CrossRef]

33. Mehrvar, M.; Bis, C.; Scharer, J.M.; Moo-Young, M.; Luong, J.H. Fiber-optic biosensors-Trends and advances. Anal. Sci. 2000, 16, 677-692. [CrossRef]

34. Arnold, M.A. Fiber-Optic Chemical Sensors. Anal. Chem. 1992, 64. [CrossRef]

35. Seitz, W.R. Chemical sensors based on fiber optics. Anal. Chem. 1984, 56, A16-A34. [CrossRef]

36. Jarzebinska, R.; Korposh, S.; James, S.; Batty, W.; Tatam, R.; Lee, S.W. Optical Gas Sensor Fabrication Based on Porphyrin-Anchored Electrostatic Self-Assembly onto Tapered Optical Fibers. Anal. Lett. 2012, 45, 1297-1309. [CrossRef]

37. Jarzebinska, R.; Cheung, C.S.; James, S.W.; Tatam, R.P. Response of the transmission spectrum of tapered optical fibres to the deposition of a nanostructured coating. Meas. Sci. Technol. 2009, 20, 34001. [CrossRef]

38. Mackenzie, H.S.; Payne, F.P. Evanescent Field Amplification in a Tapered Single-Mode Optical Fibre. Electron. Lett. 1990, 26, 130-132. [CrossRef]

39. Massaro, A.; Pierantoni, L.; Rozzi, T. Far-field radiation of optical fibers with tapered end. J. Lightwave Technol. 2006, 24, 3162-3168. [CrossRef]

40. Latifi, H.; Zibaii, M.I.; Hosseini, S.M.; Jorge, P. Nonadiabatic tapered optical fiber for biosensor applications. Photonic Sens. 2012, 2, 340-356. [CrossRef]

41. Xu, Y.; Lu, P.; Chen, L.; Bao, X. Recent developments in micro-structured fiber optic sensors. Fibers 2017, 5, 3. [CrossRef]

42. Jabbar, A.A.; Haider, A.J.; Haider, M.J.; Al-Azawi, K.F. Preparation and characterization of NiO/PSi as self-cleaning surface. J. Mater. Res. Technol. 2020, 9, 15123-15131. [CrossRef]

43. Birks, T.A.; Li, Y.W. The Shape of Fiber Tapers. J. Lightwave Technol. 1992, 10, 432-438. [CrossRef]

44. Leung, A.; Rijal, K.; Shankar, P.M.; Mutharasan, R. Effects of geometry on transmission and sensing potential of tapered fiber sensors. Biosens. Bioelectron. 2006, 21, 2202-2209. [CrossRef] [PubMed]

45. McCulloch, S.; Uttamchandani, D. Development of a fibre optic micro-optrode for intracellular pH measurements. IEE Proc. Optoelectron. 1997, 144, 162-167. [CrossRef]

46. International, S.M.; Nishitani, R.; Umeno, T.; Kasuya, A.; Nishina, Y. Correlation Between Scanning Tunneling Microscopy (STM)-Induced Photon Map and the STM Topography of Nanometer-Size Metal Particles. eCM J. 1998, $12,113$. 
47. Zhao, X.; Zhao, N.; Shi, Y.; Xin, H.; Li, B. Optical fiber tweezers: A versatile tool for optical trapping and manipulation. Micromachines 2020, 11, 114. [CrossRef] [PubMed]

48. Abushagur, A.A.G.; Arsad, N.; Mokhtar, M.H.H.; Bakar, A.A.A. High Sensitive Microsurgical Force Sensor Using Spectral-Width of Tapered Fiber Bragg Gratings. In Proceedings of the 2019 IEEE International Conference on BioPhotonics (BioPhotonics), Taipei, Taiwan, 15-18 September 2019; pp. 1-2.

49. Sun, D.; Ran, Y.; Wang, G. Label-free detection of cancer biomarkers using an in-line taper fiber-optic interferometer and a fiber bragg grating. Sensors 2017, 17, 2559. [CrossRef]

50. Mitschke, F. Fiber Optics: Physics and Technology, 2nd ed.; Springer: Berlin, Germany, 2016; ISBN 9783662527641.

51. Chen, G.Y.; Wu, X.; Kang, Y.Q.; Yu, L.; Monro, T.M.; Lancaster, D.G.; Liu, X.; Xu, H. Ultra-fast Hygrometer based on U-shaped Optical Microfiber with Nanoporous Polyelectrolyte Coating. Sci. Rep. 2017, 7, 1-7. [CrossRef]

52. Zhu, S.; Pang, F.; Huang, S.; Zou, F.; Dong, Y.; Wang, T. High sensitivity refractive index sensor based on adiabatic tapered optical fiber deposited with nanofilm by ALD. Opt. Express 2015, 23, 13880. [CrossRef]

53. He, F.; Liao, Y.; Lin, J.; Song, J.; Qiao, L.; Cheng, Y.; He, F.; Sugioka, K. Femtosecond laser fabrication of monolithically integrated microfluidic sensors in glass. Sensors 2014, 14, 19402-19440. [CrossRef] [PubMed]

54. Correia, R.; James, S.; Lee, S.W.; Morgan, S.P.; Korposh, S. Biomedical application of optical fibre sensors. J. Opt. 2018, 20. [CrossRef]

55. Black, R.J.; Lacroix, S.; Gonthier, F.; Love, J.D. Tapered single-mode fibres and devices Part 2. Experimental and theoretical quantification. IEE Proc. Part J Optoelectron. 1991, 138, 355-364. [CrossRef]

56. Harun, S.W.; Lim, K.S.; Tio, C.K.; Dimyati, K.; Ahmad, H. Theoretical analysis and fabrication of tapered fiber. Optik 2013, 124, 538-543. [CrossRef]

57. Moore, J.P.; Rogge, M.D. Shape sensing using multi-core fiber optic cable and parametric curve solutions. Opt. Express 2012, 20, 2967. [CrossRef]

58. Lavrov, V.S.; Plotnikov, M.Y.; Aksarin, S.M.; Efimov, M.E.; Shulepov, V.A.; Kulikov, A.V.; Kireenkov, A.U. Experimental investigation of the thin fiber-optic hydrophone array based on fiber Bragg gratings. Opt. Fiber Technol. 2017, 34, 47-51. [CrossRef]

59. Popov, S.M.; Butov, O.V.; Kolosovskiy, A.O.; Voloshin, V.V.; Vorob'ev, I.L.; Vyatkin, M.Y.; Fotiadi, A.A.; Chamorovskiy, Y.K. Optical fibres with arrays of FBG: Properties and application. Prog. Electromagn. Res. Symp. 2017, 1568-1573. [CrossRef]

60. Popov, S.M.; Butov, O.V.; Chamorovski, Y.K.; Isaev, V.A.; Mégret, P.; Korobko, D.A.; Zolotovskii, I.O.; Fotiadi, A.A. Narrow linewidth short cavity Brillouin random laser based on Bragg grating array fiber and dynamical population inversion gratings. Results Phys. 2018, 9, 806-808. [CrossRef]

61. Abushagur, A.A.G.; Bakar, A.A.A.; Dzulkefly Bin Zan, M.S.; Arsad, N. A Novel Technique Employing Tapered Fiber Bragg Grating to Solve the Axial/Transverse Forces Crosstalk in Microsurgical Instruments. IEEE Sens. J. 2016, 16, 7671-7680. [CrossRef]

62. Zhao, J.; Niu, P.; Zhang, C.; Sun, X.; Bai, H.; Miao, C. Temperature-compensated fiber laser refractometer based on compact hybrid S-taper/FBG structure. Opt. Fiber Technol. 2018, 45, 300-305. [CrossRef]

63. Ding, M.; Niu, P.; Yu, L.; Zhao, J.; Zhang, C. Dual-point refractive index measurement based on cascaded S fiber taper/FBG structures. Optik 2019, 183, 1120-1125. [CrossRef]

64. Zhang, W.; Zhuang, W.; Dong, M.; Zhu, L.; Meng, F. Dual-Parameter Optical Fiber Sensor for Temperature and Pressure Discrimination Featuring Cascaded Tapered-FBG and Ball-EFPI. IEEE Sens. J. 2019, 19, 5645-5652. [CrossRef]

65. Chen, M.Q.; Zhao, Y.; Xia, F.; Peng, Y.; Tong, R.J. High sensitivity temperature sensor based on fiber air-microbubble Fabry-Perot interferometer with PDMS-filled hollow-core fiber. Sens. Actuators A Phys. 2018, 275, 60-66. [CrossRef]

66. Li, W.; Yuan, Y.; Yang, J.; Yuan, L. In-fiber integrated high sensitivity temperature sensor based on long Fabry-Perot resonator. Opt. Express 2019, 27, 14675. [CrossRef] [PubMed]

67. Zhang, Y.; Zhang, Y.; Wang, Z.; Liu, Z.; Wei, Y.; Zhao, E.; Yang, X.; Zhang, J.; Yang, J.; Yuan, L. A novel Michelson Fabry-Perot hybrid interference sensor based on the micro-structured fiber. Opt. Commun. 2016, 374, 58-63. [CrossRef]

68. Zhao, Y.; Chen, M.Q.; Lv, R.Q.; Xia, F. In-fiber rectangular air fabry-perot strain sensor based on high-precision fiber cutting platform. Opt. Commun. 2017, 384, 107-110. [CrossRef]

69. Yoshino, T.; Ose, T.; Kurosawa, K.; Itoh, K. Fiber-Optic Fabry-Perot Interferometer and Its Sensor Applications. IEEE Trans. Microw. Theory Tech. 1982, 30, 1612-1621. [CrossRef]

70. Zhao, X.; Zhang, Y.; Zhang, W.; Li, Z.; Kong, L.; Yu, L.; Ge, J.; Yan, T. Ultra-high sensitivity and temperature-compensated Fabry-Perot strain sensor based on tapered FBG. Opt. Laser Technol. 2020, 124, 105997. [CrossRef]

71. Chamorovskiy, Y.K.; Butov, O.V.; Kolosovskiy, A.O.; Popov, S.M.; Voloshin, V.V.; Vorob'ev, I.L.; Vyatkin, M.Y.; Odnobludov, M.A. Long tapered fiber with array of FBG. Opt. Fiber Technol. 2019, 50, 95-98. [CrossRef]

72. Kerttula, J.; Filippov, V.; Ustimchik, V.; Chamorovskiy, Y.; Okhotnikov, O.G. Mode evolution in long tapered fibers with high tapering ratio. Opt. Express 2012, 20, 25461. [CrossRef]

73. Li, J.; Zhang, W.; Gao, S.; Geng, P.; Xue, X.; Bai, Z.; Liang, H. Long-period fiber grating cascaded to an S fiber taper for simultaneous measurement of temperature and refractive index. IEEE Photonics Technol. Lett. 2013, 25, 888-891. [CrossRef]

74. Luo, A.; Gao, K.; Liu, F.; Qu, R.; Fang, Z. Evanescent-field coupling based on long period grating and tapered fiber. Opt. Commun. 2004, 240, 69-73. [CrossRef]

75. Navruz, I.; Ari, F.; Bilsel, M.; AL-Mashhadani, Z.A. Enhancing refractive index sensitivity using micro-tapered long-period fiber grating inscribed in biconical tapered fiber. Opt. Fiber Technol. 2018, 45, 201-207. [CrossRef] 
76. Jin, X.; Sun, C.; Duan, S.; Liu, W.; Li, G.; Zhang, S.; Chen, X.; Zhao, L.; Lu, C.; Yang, X.; et al. High strain sensitivity temperature sensor based on a secondary modulated tapered long period fiber grating. IEEE Photonics J. 2019, 11, 1-8. [CrossRef]

77. Fan, P.; Sun, L.-P.; Yu, Z.; Li, J.; Wu, C.; Guan, B.-O. Higher-order diffraction of long-period microfiber gratings realized by arc discharge method. Opt. Express 2016, 24, 25380. [CrossRef] [PubMed]

78. Shu, X.; Zhang, L.; Bennion, I. Sensitivity characteristics of long-period fiber gratings. J. Lightwave Technol. 2002, 20, 255-266. [CrossRef]

79. Rego, G. A review of refractometric sensors based on long period fibre gratings. Sci. World J. 2013, 2013. [CrossRef]

80. Tian, Z.; Yam, S.S.-H.; Loock, H.-P. Refractive index sensor based on an abrupt taper Michelson interferometer in a single-mode fiber. Opt. Lett. 2008, 33, 1105. [CrossRef] [PubMed]

81. Wu, Y.; Xu, Y.; Yang, Y.; Jin, W.; Jiang, Y.; Shen, Y.; Jian, S. High-sensitivity pressure sensor based on fiber Mach-Zehnder interferometer. Meas. Sci. Technol. 2017, 28, 105102. [CrossRef]

82. Talataisong, W.; Wang, D.N.; Chitaree, R.; Liao, C.R.; Wang, C. Fiber in-line Mach-Zehnder interferometer based on an inner air-cavity for high-pressure sensing. Opt. Lett. 2015, 40, 1220. [CrossRef] [PubMed]

83. Wang, Q.; Kong, L.; Dang, Y.; Xia, F.; Zhang, Y.; Zhao, Y.; Hu, H.; Li, J. High sensitivity refractive index sensor based on splicing points tapered SMF-PCF-SMF structure Mach-Zehnder mode interferometer. Sens. Actuators B Chem. 2016, 225, 213-220. [CrossRef]

84. Raji, Y.M.; Lin, H.S.; Ibrahim, S.A.; Mokhtar, M.R.; Yusoff, Z. Intensity-modulated abrupt tapered Fiber Mach-Zehnder Interferometer for the simultaneous sensing of temperature and curvature. Opt. Laser Technol. 2016, 86, 8-13. [CrossRef]

85. Liao, C.R.; Chen, H.F.; Wang, D.N. Ultracompact optical fiber sensor for refractive index and high-temperature measurement. J. Lightwave Technol. 2014, 32, 2531-2535. [CrossRef]

86. Hu, T.Y.; Wang, Y.; Liao, C.R.; Wang, D.N. Miniaturized fiber in-line Mach-Zehnder interferometer based on inner air cavity for high-temperature sensing. Opt. Lett. 2012, 37, 5082. [CrossRef] [PubMed]

87. Liao, C.; Zhu, F.; Zhou, P.; Wang, Y. Fiber taper-based mach-zehnder interferometer for ethanol concentration measurement. Micromachines 2019, 10, 741. [CrossRef] [PubMed]

88. Li, B.; Jiang, L.; Wang, S.; Mengmeng Wang, Q.C.; Yang, J. A new Mach-Zehnder interferometer in a thinned-cladding fiber fabricated by electric arc for high sensitivity refractive index sensing. Opt. Lasers Eng. 2012, 50, 829-832. [CrossRef]

89. Men, L.; Lu, P.; Chen, Q. Femtosecond laser trimmed fiber taper for simultaneous measurement of axial strain and temperature. IEEE Photonics Technol. Lett. 2011, 23, 320-322. [CrossRef]

90. Lu, P.; Chen, Q. Femtosecond laser microstructured fibre refractive index sensor with temperature compensation. Electron. Lett. 2010, 46, 1616-1617. [CrossRef]

91. Yingyu Yu, Y.Y.; Lan Jiang, L.J.; Benye Li, B.L.; Zhitao Cao, Z.C.; Sumei Wang, S.W. Fiber inline interferometric refractive index sensors fabricated by femtosecond laser and fusion splicing. Chin. Opt. Lett. 2013, 11, 110603-110606. [CrossRef]

92. Salazar Sicacha, M.; Minkovich, V.P.; Sotsky, A.B.; Shilov, A.V.; Sotskaya, L.I. Transmittance of tapered photonic crystal fibers with absorbing coatings. EPJ Web Conf. 2020, 238, 08005. [CrossRef]

93. Fu, G.; Fu, X.; Guo, P.; Ji, Y.; Bi, W. Research on Fused Tapered Photonic Crystal Fiber Sensor Based on the Method of Intermittent Cooling. J. Sens. 2016, 2016. [CrossRef]

94. Mägi, E.C.; Steinvurzel, P.; Eggleton, B.J. Tapered photonic crystal fibers. Opt. Express 2004, 12, 776. [CrossRef]

95. Bondu, M.; Brooks, C.; Jakobsen, C.; Oakes, K.; Moselund, P.M.; Leick, L.; Bang, O.; Podoleanu, A. High energy supercontinuum sources using tapered photonic crystal fibers for multispectral photoacoustic microscopy. J. Biomed. Opt. 2016, $21,061005$. [CrossRef] [PubMed]

96. Li, C.; Qiu, S.J.; Chen, Y.; Xu, F.; Lu, Y.Q. Ultra-sensitive refractive index sensor with slightly tapered photonic crystal fiber. IEEE Photonics Technol. Lett. 2012, 24, 1771-1774. [CrossRef]

97. Ni, K.; Chan, C.C.; Dong, X.; Poh, C.L.; Li, T. Temperature-independent refractometer based on a tapered photonic crystal fiber interferometer. Opt. Commun. 2013, 291, 238-241. [CrossRef]

98. Feng, C.; Feng, G.-Y.; Zhou, G.-R.; Chen, N.-J.; Zhou, S.-H. Design of an ultracompact optical gas sensor based on a photonic crystal nanobeam cavity. Laser Phys. Lett. 2012, 9, 875-878. [CrossRef]

99. Neseli, B.; Bor, E.; Kurt, H.; Turduev, M. Transmission enhanced wavelength demultiplexer design based on photonic crystal waveguide with gradually varied width. In Proceedings of the 2019 21st International Conference on Transparent Optical Networks (ICTON), Angers, France, 9-13 July 2019; pp. 1-4.

100. Homola, J.; Piliarik, M. Surface Plasmon Resonance (SPR) Sensors; Springer: Berlin/Heidelberg, Germany, 2006 ; ISBN 9783540339182.

101. Kretschmann, E.; Raether, H. Radiative Decay of Non Radiative Surface Plasmons Excited by Light. Z. Nat. Sect. A J. Phys. Sci. 1968, 23, 2135-2136. [CrossRef]

102. Mauriz, E.; Calle, A.; Lechuga, L.M.; Quintana, J.; Montoya, A.; Manclús, J.J. Real-time detection of chlorpyrifos at part per trillion levels in ground, surface and drinking water samples by a portable surface plasmon resonance immunosensor. Anal. Chim. Acta 2006, 561, 40-47. [CrossRef]

103. Wang, S.; Shan, X.; Patel, U.; Huang, X.; Lu, J.; Li, J.; Tao, N. Label-free imaging, detection, and mass measurement of single viruses by surface plasmon resonance. Proc. Natl. Acad. Sci. USA 2010, 107, 16028-16032. [CrossRef] [PubMed]

104. Prabowo, B.A.; Wang, R.Y.L.; Secario, M.K.; Ou, P.T.; Alom, A.; Liu, J.J.; Liu, K.C. Rapid detection and quantification of Enterovirus 71 by a portable surface plasmon resonance biosensor. Biosens. Bioelectron. 2017, 92, 186-191. [CrossRef] [PubMed] 
105. Lin, H.-Y.; Huang, C.-H.; Cheng, G.-L.; Chen, N.-K.; Chui, H.-C. Tapered optical fiber sensor based on localized surface plasmon resonance. Opt. Express 2012, 20, 21693. [CrossRef] [PubMed]

106. Musa, N.; Safwan Abd Aziz, M.; Bakhtiar, H.; Krishnan, G.; Hafiz Dzafran Othman, M.; Rahman, M.A.; Fauzi Ismail, A. Performance of Single Mode Tapered Optical Fiber Sensor Based on Localized Surface Plasmon Resonance (LSPR) for Various Coating Time. J. Phys. Conf. Ser. 2020, 1484. [CrossRef]

107. Wang, Q.; Farrell, G.; Yan, W. Investigation on single-mode-multimode-single-mode fiber structure. J. Lightwave Technol. 2008, 26, 512-519. [CrossRef]

108. Wang, P.; Brambilla, G.; Ding, M.; Semenova, Y.; Wu, Q.; Farrell, G. Investigation of single-mode-multimode-single-mode fiber structures and their application for refractive index sensing. America 2011, 28, 1180-1186.

109. Zhao, Y.; Cai, L.; Hu, H.F. Fiber-Optic Refractive Index Sensor Based on Multi-Tapered SMS Fiber Structure. IEEE Sens. J. 2015, 15, 6348-6353. [CrossRef]

110. Sun, G.; Wu, G.; Wang, F.; Tang, R.; Qiu, G. High-Stress Resistance Fiber Refractometer Based on MMF Sandwiched between Two SMF Half-Tapers. IEEE Photonics Technol. Lett. 2016, 28, 1336-1339. [CrossRef]

111. Kang, J.; Yang, J.; Zhang, X.; Liu, C.; Wang, L. Intensity demodulated refractive index sensor based on front-tapered single-modemultimode-single-mode fiber structure. Sensors 2018, 18, 2396. [CrossRef] [PubMed]

112. Silva, S.O.; Magalhães, R.; Marques, M.B.; Frazão, O. New advances in fiber cavity ring-down technology. Opt. Laser Technol. 2016, 78, 115-119. [CrossRef]

113. Wu, D.; Zhao, Y.; Wang, Q. SMF Taper Evanescent Field-Based RI Sensor Combined with Fiber Loop Ring Down Technology. IEEE Photonics Technol. Lett. 2015, 27, 1802-1805. [CrossRef]

114. Niu, P.; Zhao, J.; Zhang, C.; Bai, H.; Sun, X.; Bai, J.; Chen, L. S Fiber Taper-Based Fiber Loop Ring-Down Refractometer. IEEE Sens. J. 2019, 19, 970-975. [CrossRef]

115. Tian, J.; Yang, L.; Qin, C.; Wu, T.; Wang, J.; Zhang, Z.; Li, K.; Copner, N.J. Refractive Index Sensing Based on Chaotic Correlation Fiber Loop Ring down System Using Tapered Fiber. IEEE Sens. J. 2020, 20, 4215-4220. [CrossRef]

116. Li, Y.C.; Xin, H.B.; Lei, H.X.; Liu, L.L.; Li, Y.Z.; Zhang, Y.; Li, B.J. Manipulation and detection of single nanoparticles and biomolecules by a photonic nanojet. Light Sci. Appl. 2016, 5, 1-9. [CrossRef]

117. Li, Y.; Xin, H.; Zhang, Y.; Lei, H.; Zhang, T.; Ye, H.; Saenz, J.J.; Qiu, C.W.; Li, B. Living Nanospear for Near-Field Optical Probing. ACS Nano 2018, 12, 10703-10711. [CrossRef]

118. Liu, S.; Li, Z.; Weng, Z.; Li, Y.; Shui, L.; Jiao, Z.; Chen, Y.; Luo, A.; Xing, X.; He, S. Miniaturized optical fiber tweezers for cell separation by optical force. Opt. Lett. 2019, 44, 1868-1871. [CrossRef] [PubMed]

119. Liang, P.B.; Lei, J.J.; Liu, Z.H.; Zhang, Y.; Yuan, L.B. A study of multi-trapping of tapered-tip single fiber optical tweezers. Chin. Phys. B 2014, 23. [CrossRef]

120. Lou, Y.; Wu, D.; Pang, Y. Optical Trapping and Manipulation Using Optical Fibers. Adv. Fiber Mater. 2019, 1, 83-100. [CrossRef]

121. Zhang, C.; Xu, B.; Gong, C.; Luo, J.; Zhang, Q.; Gong, Y. Fiber optofluidic technology based on optical force and photothermal effects. Micromachines 2019, 10, 499. [CrossRef]

122. Asadollahbaik, A.; Thiele, S.; Weber, K.; Kumar, A.; Drozella, J.; Sterl, F.; Herkommer, A.M.; Giessen, H.; Fick, J. Highly Efficient Dual-Fiber Optical Trapping with 3D Printed Diffractive Fresnel Lenses. ACS Photonics 2019. [CrossRef]

123. Korposh, S.; James, S.W.; Lee, S.W.; Tatam, R.P. Tapered Optical Fibre Sensors: Current Trends and Future Perspectives. Sensors 2019, 19, 2294. [CrossRef] [PubMed]

124. Maragò, O.M.; Jones, P.H.; Gucciardi, P.G.; Volpe, G.; Ferrari, A.C. Optical trapping and manipulation of nanostructures. Nat. Nanotechnol. 2013, 8, 807-819. [CrossRef]

125. Tong, L. Micro/nanofibre optical sensors: Challenges and prospects. Sensors 2018, 18, 903. [CrossRef] [PubMed]

126. Lakomski, M.; Guzowski, B.; Wozniak, A. Fabrication of ultra-long tapered optical fibers. Microelectron. Eng. 2020, 221, 111193. [CrossRef]

127. Xiong, Y.; Xu, F. Multifunctional integration on optical fiber tips: Challenges and opportunities. Adv. Photonics 2020, 2, 1-24. [CrossRef]

128. Hu, Q.; Li, C. The New Tapered Fiber Connector and the Test of Its Error Rate and Coupling Characteristics. Int. J. Opt. 2017, 2017. [CrossRef]

129. Li, T.; Zhu, L.; Yang, X.; Lou, X.; Yu, L. A refractive index sensor based on h-shaped photonic crystal fibers coated with ag-graphene layers. Sensors 2020, 20, 741. [CrossRef] [PubMed] 